\title{
Applying Solar Energy in the Combination of Solar Dryer with Olive Harvesting Machine to Reduce Energy Losses
}

\author{
Fatemeh Zare ${ }^{1}$, Gholamhassan Najafi ${ }^{1}$, Pedram Ghiasi ${ }^{1}$, Ebrahim Fayyazi ${ }^{1}$, Talal Yusaf ${ }^{2, *}$ \\ and Mohamed Mazlan ${ }^{3, *}$ \\ 1 Department of Biosystems Engineering, Tarbiat Modares University (TMU), Tehran 14115-111, Iran; \\ F.Zare@modares.ac.ir (F.Z.); g.najafi@modares.ac.ir (G.N.); p.ghiasi@modares.ac.ir (P.G.); \\ E.Fayyazi@modares.ac.ir (E.F.) \\ 2 School of Engineering and Technology, Central Queensland University, Brisbane 4009, Australia \\ 3 Faculty of Bioengineering and Technology, Advanced Material Research Cluster, \\ Universiti Malaysia Kelantan, Jeli 17600, Malaysia \\ * Correspondence: t.yusaf@cqu.edu.au (T.Y.); mazlan.m@umk.edu.my (M.M.)
}

check for updates

Citation: Zare, F.; Najafi, G.; Ghiasi, P.; Fayyazi, E.; Yusaf, T.; Mazlan, M Applying Solar Energy in the Combination of Solar Dryer with Olive Harvesting Machine to Reduce Energy Losses. Sustainability 2022, 14, 1091. https://doi.org/10.3390/ su14031091

Academic Editors: Tomonobu Senjyu and Alessandro Franco

Received: 30 November 2021

Accepted: 4 January 2022

Published: 18 January 2022

Publisher's Note: MDPI stays neutral with regard to jurisdictional claims in published maps and institutional affiliations.

Copyright: (C) 2022 by the authors. Licensee MDPI, Basel, Switzerland. This article is an open access article distributed under the terms and conditions of the Creative Commons Attribution (CC BY) license (https:// creativecommons.org/licenses/by/ $4.0 /)$.

\begin{abstract}
In recent years, leveraging the amount of energy loss occurring in different fields of human activity has captured the attention of researchers. Harvesting and drying processes can be integrated in order to reduce energy losses. The present research work seeks to pinpoint the association between the harvesting and drying processes as well as to make optimal use of both processes so as to decrease the level of energy loss and apply the renewable energies to the food supply chain. The olive harvesting machine was designed and evaluated, and the olives harvested in the solar dryer were placed in the solar dryer as the input materials. To obtain the evaluation of the experimental tests' purpose, Mari cultivar was used. Following this trend was the evaluation of the olive harvesting machine and its comparison with the manual harvesting method. Having separated the olives from the tree through use of the harvesting machine designed and made, a solar dryer was used to accommodate the olives in order to make the final examination concerning any damage to olives. Findings of the study indicated up to $92 \%$ separation of the olive fruits by the olive harvester. It was also found that there is a 29.47 harvest efficiency for the olive harvester. In addition, evaluation of the solar dryer emphasized that an increase in the temperature and velocity of the inlet air results in a rapid decrease in the olive moisture.
\end{abstract}

Keywords: continuous processes; renewable energy in agriculture; olive fruit storage

\section{Introduction}

In the field of energy, agriculture is believed to be among the high-consuming industries. The determinants of energy consumption are the population involved in agriculture, the number of arable areas, and the level of mechanization. Furthermore, when there is a bulky chain of production concerning the final product, lower levels of energy consumption can be expected. Renewable energies are regarded as alternative sources of energy to fossil fuel [1], which include solar energy, wind energy, biomass energy, geothermal energy, etc. [2]. Solar energy is deemed to be a common energy source, and it can be found in various countries [3]. Solar collectors can collect solar energy and produce applicable heat. The outcome of collecting the heat through the solar collectors is the generation of power, desalination, and drying [4]. Drying is classified by its high level of energy consumption when the crop-producing processes category is addressed [5]. When referring to the drying process of horticultural crops, it is observable that direct sunlight and high temperatures can damage the active ingredients existing in the plant. Accordingly, the main horticulture crops, namely olive fruits, can be obtained in canned, dried fruit, and oil extraction forms [6]. There are three features, including the harvesting, drying, and the time interval, that render the olive plant for consumption [7]. In the case of fully mechanized harvesting, it is feasible 
to have the economic success of super-intensive olive plantations [8]. Olive harvesting is not a cost-effective process, and a number of problems accompany it, such as damages to fruit and to the olive tree, mitigation of quality, injuries to individuals, consumption of time, and expenses present in adhering to the conventional methods [9]. The drying process is attended through the incorporation of an electrical device, which means it falls into the high-energy process category. When compared to other crop-producing processes, it makes use of the maximum energy level [10]. The subcategories of renewable energy (which are solar energy, wind energy, biomass energy, geothermal energy, etc.) can be taken into consideration when it comes to resolving the problems of energy consumption involved in the aforementioned process [7]. The harvesting method has been meticulously given attention in terms of the shaker design, harvesting efficiency estimation, tree damage, and energy consumption. Practically, the extent to which the shaking force and shaking amplitude could affect mechanized olive harvesting was put forth in a study, which showed that as the olive tree diameter increased, the shaking force and shaking amplitude were increased and decreased, respectively. It was suggested in this study that there should be higher levels of power used in case of large olive trees with large trunk diameters [11]. Another study tackled different manners in which olive harvesting could be performed, and it was concluded that stem shaking is the best method to remove the olive fruit from a tree with a low level of energy consumption [12]. As regards the different categories of olive harvesting, one study illustrated that the flat-type olive harvester enjoys the highest vibration value index [10]. Productivity and energy consumption can be specified on the basis of the time, which is a significant element in the harvesting process. In this regard, another study was shaped to investigate the effect of olive tree harvesting tools, namely, trunk shaker and mechanical harvest aid, with respect to time [13]. The study was performed through the lenses of the mechanical canopy and trunk shaking related to the harvesting mechanization of table olive orchards. From the trunk shaker accumulation and shaker combs perspective, the outcomes of the study represented an increase in the bruise index of olive fruits. Therefore, it is possible to argue that the lowest bruise index of olive fruits is $0.5 \%$, the value of the manual-type harvester [14].

The performance of a dish concentrator with cavity receivers has been addressed by various researchers [15,16]. As an example, Pavolic et al. [17] sought to pinpoint the optical and thermal performance of a dish concentrator featuring two shapes of cavity receiver, conical and spiral, and it was suggested that the use of the dish concentrator with the conical cavity receiver leads to a higher thermal performance. In another attempt, Loni et al. [18] drew their attention toward the performance of a dish concentrator with different shapes of cavity receiver and various solar working fluids. In particular, three categories of cavities, including hemispherical, cylindrical, and cubical, accompanied by water and thermal oil as different heat transfer fluids were studied. It was found that when high temperature exists, the highest exergy efficiency can be attributed to the thermal oil. Focusing on energy and exergy, Venkatachalam and Cheralathan [19] investigated a dish concentrator with a conical cavity receiver, and the aspect ratio with different amounts was studied. As the outcomes represented, the aspect ratio is of immense significance when one addresses solar dish performance. The overall objective of the study led by Yan et al. [20] was to optimize the solar heat flux distribution on cavity walls of a dish contractor as far as the highest performance was concerned. For the purpose of optimization, the researchers used a genetic algorithm and reported an increase in optical efficiency and uniformity of solar flux distribution on the cavity receiver. Furthermore, Yan et al. [21] intended to find a new design of a dish concentrator with a cavity receiver. Accordingly, Loni et al. [22] endeavored to evaluate and optimize the optical and thermal performance of a dish concentrator with a rectangular cavity receiver as a heat source of an ORC system for power generation. What the authors suggested to attain the maximum performance was the consideration of optimum structural and operational parameters. Focusing on a numerical study, Karimi et al. [23] conducted a study to investigate a dish concentrator with a cylindrical cavity receiver. The performance of the solar dish system 
was in question regarding the influence of different operational and structural parameters. Similar researchers such as [24], who contemplated smooth and corrugated types of cavity tubes, have looked into the exegetical performance of a dish concentrator with a spiral receiver and decided that a better performance can be attributed to the solar system including the spiral cavity receiver with a corrugated tube.

Nanofluids, defined as suspension fluids of nanoparticles in a base fluid such as water, oil, or propylene glycol, share important features concerning solar system performance and can be used in this field [25]. Several researchers have attended to the investigation of nanofluids as the solar working fluid of solar collectors [26-28]. Some other researchers such as Loni et al. $[29,30]$ surveyed the use of various nanofluids, including $\mathrm{Al}_{2} \mathrm{O}_{3} /$ oil and $\mathrm{SiO}_{2} /$ oil nanofluids, so as to obtain the performance of a dish concentrator with cylindrical and hemispherical cavity receivers. Performance of dish was accompanied by several experimental relationships. Ultimately, the use of nanofluid, compared to pure oil as the solar working fluid, was proved to improve the performance of the solar system.

Researchers who deal with energy and agriculture review energy consumption reduction and agricultural processes centralization as two key entities. An integration of the various agricultural processes to mitigate energy and material losses was put into practice concerning the soil and planting crops preparation process. There is a new approach toward olive production, i.e., merging the harvesting and drying operations continuously without interruption. One of the primary intentions of the current research work was to integrate the harvesting and drying processes as well as to incorporate renewable energy as far as the final product preparation process is concerned. Nevertheless, the absence of a proper olive harvesting machine inspired the idea to design and construct a new pneumatic machine for the purpose of olive harvesting, and this was pursued by studying the olives' processing in a solar dryer. For the sake of this matter, to design the olive harvesting machine, initially a proper and safe frequency in line with the vibration of the jaw of the machine was attended by simulation in Ansys software, and then a pneumatic design was completed in order to yield this frequency. Outcomes of olive harvesting machine assessment, including the harvesting efficiency, harvesting productivity, and damage to the olive tree, were inspected individually through the manual harvesting.

The role played by a dish concentrator with a cavity receiver in heating a dryer was studied. To fulfill the dish absorber role, a cylindrical cavity receiver was used. Pure thermal oil and $\mathrm{Al}_{2} \mathrm{O}_{3}$ / oil nanofluid, taken as working fluids, were examined as the solar heat transfer fluid. Last but not least, the drying process of a solar dryer was scrutinized in the current study.

The novelty of the present study is highlighted clearly in the following elements: (1) performing the numerical simulation to determine the minimum frequency for the damage in order to reduce the consumed energy of the harvesting process; (2) designing and developing a new model of olive harvesting machine; (3) mixing the harvesting and drying processes as continuous.

\section{Materials and Methods}

\subsection{Physical and Mechanical Properties of Olives}

Measuring the fruit dimensions of each cultivar was performed by choosing 30 olives in a random manner and measuring through the use of MITUTOYO digital caliper with the following features: measuring accuracy of $0.01 \mathrm{~mm}$, length (L), width (W), and thickness (T) (Figure 1). By using a digital scale with an accuracy of $0.01 \mathrm{~g}$, a measurement was made of the fruit mass. Based on Equation (1) [31,32], the following were estimated: the arithmetic mean diameter $\left(D_{\mathrm{a}}\right)$, geometric mean diameter $\left(D_{g}\right)$, and sphericity $(\Phi)$.

$$
D_{\mathrm{a}}=\frac{\mathrm{L}+\mathrm{W}+\mathrm{T}}{3}
$$


where: $\mathrm{L}=$ the olive length $(\mathrm{mm}), \mathrm{W}=$ the olive width $(\mathrm{mm}), \mathrm{T}=$ the olive thickness $(\mathrm{mm})$, $D_{\mathrm{a}}=$ the arithmetic mean diameter $(\mathrm{mm})$.

$$
D_{g}=(\mathrm{LWT})^{\frac{1}{3}}
$$

where: $D_{g}=$ the geometric mean diameter $(\mathrm{mm})$.

$$
\Phi=\frac{(L W T)^{1 / 3}}{L}
$$

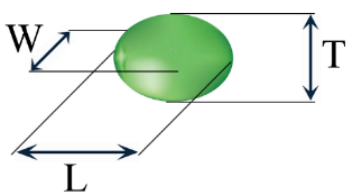

Figure 1. Dimensions of olive.

Dividing the mass of the fruit by the total volume gives the physical specific density $P_{\mathrm{b}}$. The physical specific density was measured through the olive fruit filling into an empty cylinder with a specified volume. In addition, dividing the mass of the samples by the volume of the container yields the physical specific density. The true density was obtained from Equation (4), and the sample volume was estimated by Equation (5) using liquid (water) displacement volume method.

$$
P_{\mathrm{t}}=\frac{\mathrm{mP}_{\mathrm{w}}}{\mathrm{m}_{\mathrm{w}}}
$$

where: $P_{\mathrm{t}}=$ true density $\left(\frac{\mathrm{kg}}{\mathrm{m}^{3}}\right), \mathrm{m}=$ olive mass $(\mathrm{gr})$, water density, $\mathrm{m}_{\mathrm{w}}=$ displaced water mass (gr).

$$
V=\frac{\mathrm{m}_{\mathrm{w}}}{\mathrm{P}_{\mathrm{w}}}
$$

where: $\mathrm{m}_{\mathrm{w}}=$ discalced water mass $(\mathrm{gr}), V=$ olive volume $\left(\mathrm{mm}^{3}\right)$.

The static friction coefficient $(\mu)$ was calculated by measuring the angles at which the threshold product moves on the surfaces of various materials such as wood, steel sheet, and galvanized sheet. To measure this variable, the fruits were placed in a cardboard box that had no contact with the surface, and then the surface began to rotate around a hinged axis at a uniform speed. The tangent of the angle at which the product is at the threshold of moving equals to the coefficient of static friction [31]. To determine the mechanical behavior of olives, Santam SMT-20 and $100 \mathrm{kgf}$ Loadecell material test device with an accuracy of $0.03 \mu \mathrm{m}$ was used. The device consists of three main parts, namely a fixed plate, a moving plate by which force is applied to the fruit, and a screen that displays the results (Figure 2). The olives were placed on a fixed plate, pressed by a moving plate until the olive peel was broken, and the force-deformation diagram was recorded. Five replications were performed for each sample. Fracture force and energy were displayed on the computer; the fracture energy was equal to the area below the force-deformation diagram, and the toughness was obtained through dividing the fracture energy by the volume of each sample [33]. 


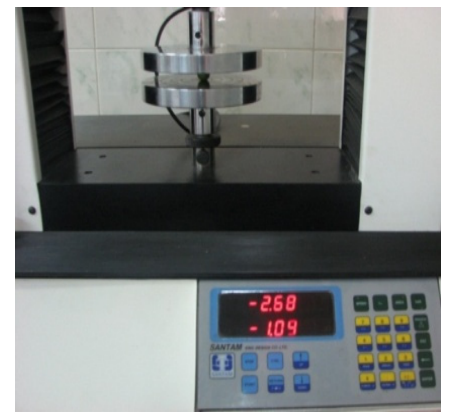

Figure 2. Mechanical behavior test process.

In order to measure the force required to separate the olive fruit from the branch, 10 olives per day were randomly selected from different parts of the canopy of each plot, and the force required to separate them was measured by a mechanical force dynamometer. The force was measured in such a way that a cotton thread of fixed length was attached to the dynamometer and the other end to the joint of the fruit to the peduncle. Then, by pulling the dynamometer ring and separating the fruit from the peduncle, the force indicated by the dynamometer was read. The dynamometer used by the Precision Process Measurement Calibration Laboratory, with certification number 681 from the Iranian Institute of Standards, was calibrated.

\subsection{Simulation}

To perform the simulation, initially the model was developed in SolidWorks software and then in ANSYS software 17.2. The olive fruit was drawn in SolidWorks software based on the calculated physical properties explained by the equations in Section 2.1. To save time in each simulation, only two fingers of the harvesting machine jaw were modeled in SolidWorks software. Figure 3 shows the isometric view of the olive fruit and the jaw of the harvesting machine at the contact angle (45) and the angle with the horizon 0 degrees. After modeling in SolidWork software, the schematic of olive parts and fruits were imported into ANSYS software. A new material was defined for the olive cultivar used based on the obtained mechanical properties. Polyester material was selected for the harvesting machine jaw, and its rigidity model was selected as rigid.

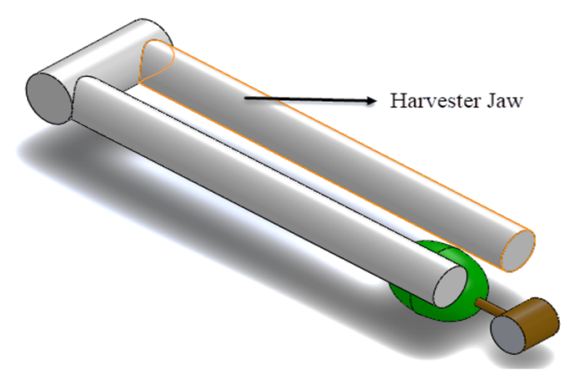

(B)

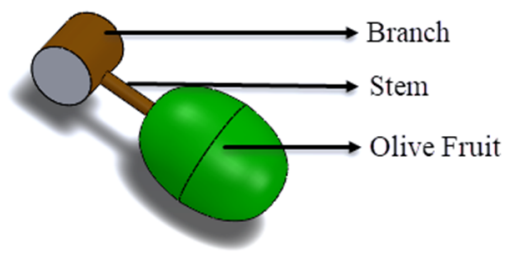

(A)

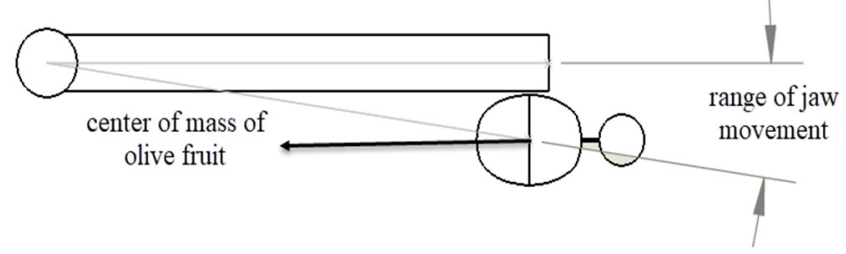

(C)

Figure 3. (A) isometric view of the olive fruit; (B) olive fruit and harvester jaw; (C) range of jaw movement. 
Primarily, the most unsuitable status for the positioning of the olive relative to the jaw was determined. For this purpose, two parameters, namely the angle of contact of the jaw with the olive and the horizontal angle of the position of the olive, were considered as variables. A schematic of these parameters is shown in Figure 4. After performing the simulation at a rotational speed of 3.2 radians per second, the position in which the stress at the location of the olive stalk is minimal was selected. The movement of the jaw was limited to the center of gravity of the olive, and for all tests this point was defined as the condition for the end of the simulation. The contact angle of the jaw with olives was determined at two levels $\left(90^{\circ}\right.$ and $\left.45^{\circ}\right)$ and the horizontal angle of placement of olives at three levels $\left(0^{\circ}, 45^{\circ}\right.$, and $\left.-45^{\circ}\right)$.

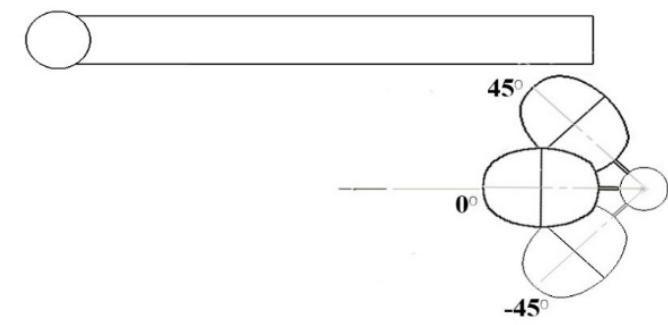

(A)

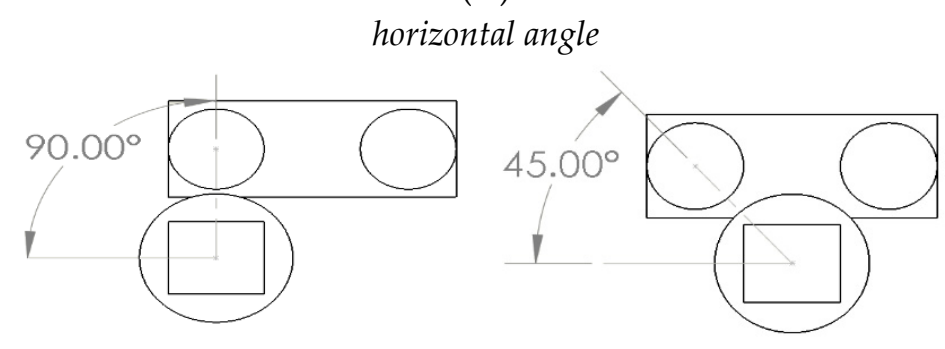

(B)

contact angle

Figure 4. (A) the horizontal angle of placement of olives; (B) the contact angle of placement of olives.

To investigate the effect of rotational speed on olive separation from the branch and to find the minimum rotational speed for the jaw of the olive harvesting machine, the position introduced in the previous step was used. Stress at two points on the olive is important to determine the rotational speed of the jaw of the machine; the first point is the connection point to the fruit stalk, and the second point is the one where the fruit comes in contact with the harvesting machine jaw. To examine this, 7 levels of rotational speed of the device jaw (3.5 to 9.5 radians per second with 1 radian per second step) were simulated, and the stresses created at the two points were investigated. The effect related to falling from a tree on olive fruit was also simulated. For this purpose, having the average height of yellow cultivar olive fruit trees and the physical properties of olives, the stress derived from the impact on the ground was investigated.

\subsection{Network Independence}

To select the number of elements and nodes suitable for simulation, geometry was created with the number of nodes and low elements, and the maximum stress value was recorded. Subsequently, by increasing the number of nodes and elements in the network, the effect of the number of nodes and elements on the maximum stress value was investigated. Finally, the numbers of nodes and elements to be independent from the mesh network were selected as 6163 and 31,475, respectively (Table 1). 
Table 1. Various mesh type properties.

\begin{tabular}{ccc}
\hline Mesh Type & Element & Node \\
\hline 1 & 11,011 & 2156 \\
2 & 19,930 & 3986 \\
3 & 31,475 & 6163 \\
4 & 40,132 & 7869 \\
\hline
\end{tabular}

\subsection{Harvester Machine Design}

The main criteria for designing the new pneumatic harvester (NPH) were as follows: easy design, simple to use, low weight, high productivity, less fruit damage, and low operating costs. The main novelty of this type of harvester is low operating costs and use in gardens far from energy networks. A double-sided jack was used to provide jaw movement, so the required airflow rate, pressure drop, airflow control valve, and jack size must be defined. Effect of number of elements and nodes on maximum stress have been shown at Figure 5.

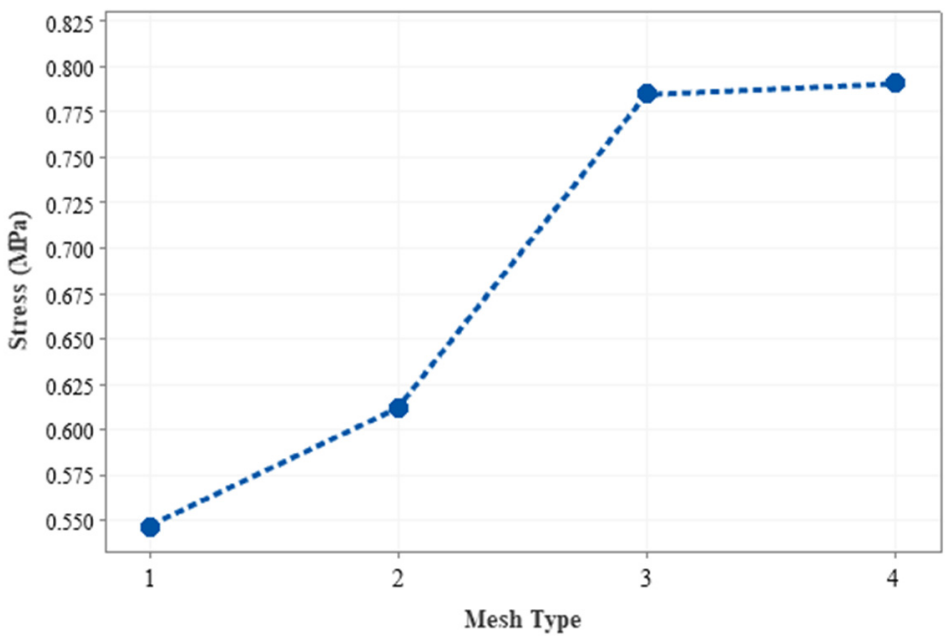

Figure 5. Effect of number of elements and nodes on maximum stress.

To compare the advantages and disadvantages of the present device with existing devices, the results of the evolution of the NPH compared with a pneumatic harvester (PH) that the features of the $\mathrm{PH}$ are shown in Table 2.

Table 2. PH technical features.

\begin{tabular}{ccc}
\hline Number & Feature & Amount \\
\hline 1 & Model & Campagnola srl \\
2 & Weight & $1 \mathrm{~kg}$ \\
3 & Length & $1.8-3 \mathrm{~m}$ \\
4 & Max pressure & $7 \mathrm{bar}$ \\
\hline
\end{tabular}

This valve can work through making changes in the airflow direction, which are classified as follows: 1 . Number of ways, 2 . Number of pulley positions, 3. Valve operation method, 4. Diameter of the valves.

\section{Jack Design}

The first step for jack design was to define the required pressure and velocity of air to detach the olives from the tree. After estimating the most appropriate rotational speed for the device jaw, the cam length and Air Mass Flow (AMF) were calculated. The amount of AMF for jaw movement to open the jaw was calculated by Equation (6), and in the closed 
cycle, Equation (7) was used for the AMF. Finally, the total AMF to open and close the jaws was calculated by Equation (8).

$$
\begin{gathered}
Q_{e x t}=\pi \times\left(\frac{D^{2}}{4}\right) \times x \times n \times\left(\frac{P_{1}-P_{0}}{P_{0}}\right) \\
Q_{e x t}=\pi \times\left(\frac{D^{2}-d^{2}}{4}\right) \times x \times n \times\left(\frac{P_{1}-P_{0}}{P_{0}}\right) \\
Q_{t o t}=\pi \times\left(\frac{2 D^{2}-d^{2}}{4}\right) \times x \times n \times\left(\frac{P_{1}-P_{0}}{P_{0}}\right)
\end{gathered}
$$

Assuming that the total pneumatic energy was converted to kinematic energy, the total energy required was calculated by Equation (9):

$$
E=\frac{\frac{1}{2} P . \pi D^{2} \cdot(0.5)^{2}}{6 g}
$$

The determinations show that the detachment force of olive fruit from the tree and the pressure required for the pneumatic jack were $10 \mathrm{~N}$ and 7 bar, respectively. The machine had one handle, and it was gripped by one operator's hand and a telescoping rod up to a maximum length of $3 \mathrm{~m}$. The harvesting mechanism had two jaws, and each jaw contained 7 fingers that allowed for easy and deep access to all types of foliage without getting caught in the branches. The angle between two jaws was selected as 90 degrees based on the previous research. The jaws had $18 \mathrm{~cm}$ length, and the distance between them must be equal to the olive fruit width, so $1 \mathrm{~cm}$ distance was considered. We assume that in every impact of jaws, 23 olive fruits were detached from tree branches. The amount of force of each jaw for the olive fruit detached from the tree was $325.3 \mathrm{~N}$. After determining the piston diameters, the length of the cam was calculated, and the standard jack with these characters was selected.

The cylinder provides a closed system which assists the movement of the piston. For moving the piston across the cylinder at high frequency, valves must be used or the manual control applied. Because of the operation conditions, the pneumatic valve was selected to change the airflow direction. When the pneumatic valve was in position A, high air pressure pushed the piston to the right side (Figure 6). By moving the piston to the right, the airflow was transferred to the $C$ input of the pneumatic valve, which changed the direction of airflow, resulting in the activation of the $\mathrm{B}$ position of the pneumatic valve. When high-pressure air moves to the B output of the pneumatic valve, the piston moves to the left side, air moves toward the D input of the pneumatic valve, and such a cycle is replicated. After assembling the parts and determining the best angular velocity of jaw movements, the frequencies of these cycles were selected and measured by an electronic eyes sensor. The frequency of the piston movement is $5.21 \mathrm{~Hz}$ in $7 \mathrm{bar}$ air pressure. This frequency provides $6.5 \mathrm{rad} \cdot \mathrm{s}^{-1}$ of jaw angular velocity. Therefore, after defining design parameters, the mechanical value of No. G1/8" was selected. Other parts of the harvester such as the chain, cam, and pneumatic valve along with the previously mentioned parts were designed. 


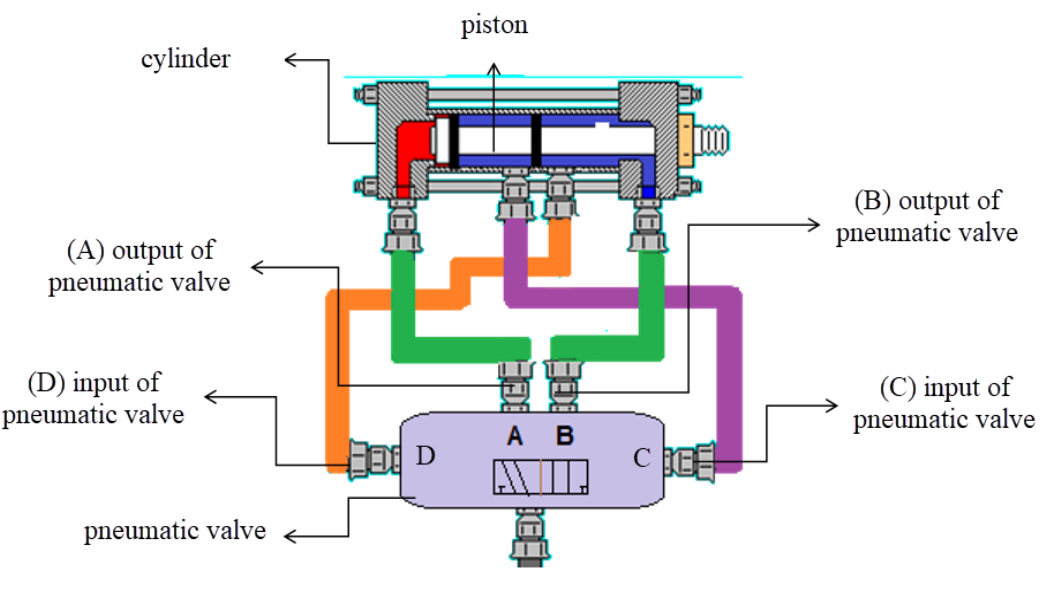

input from compressor

Figure 6. Schematic of the piston, cylinder, valve, and connector pipes.

Figure 7 shows the details of NPH, including harvester jaws, cylinder and pneumatic valve, power transmission, and telescoping rod.

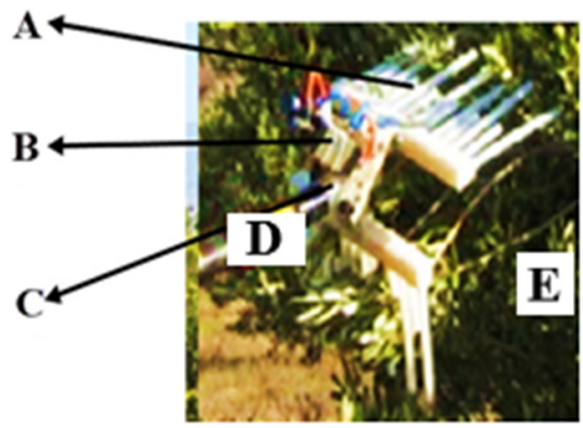

Figure 7. The parts of the NPH. (A): Harvester Jaws. (B): Cylinder and Pneumatic Valve. (C): Power Transmission Part. (D): Telescoping Rod. (E): Olive Tree.

The common properties of the collector system for olive fruit are shown in Table 3. By applying this system, the olive fruits falling from the tree were collected into a box. The driving power of the collector system is provided by labor. As suggested in Figure 8, the collector system is ready to collect the fruits in the box. The collector system includes the wheels, steering wheel, bendable bars, wire for hold cover, polyester cover, trunk holder, position for boxes, and outlet, all of which are assembled on chassis. Collector system properties have been described at Table 3 .

Table 3. Collector system properties.

\begin{tabular}{cc}
\hline Parameters & Value \\
\hline Chasses length & $140 \mathrm{~cm}$ \\
Chasses width & $95 \mathrm{~cm}$ \\
Trunk holder height & $60 \mathrm{~cm}$ \\
Trunk diameter & $\mathrm{Up} \mathrm{to} 40 \mathrm{~cm}$ \\
Cover diameter & $300 \mathrm{~cm}$ \\
\hline
\end{tabular}




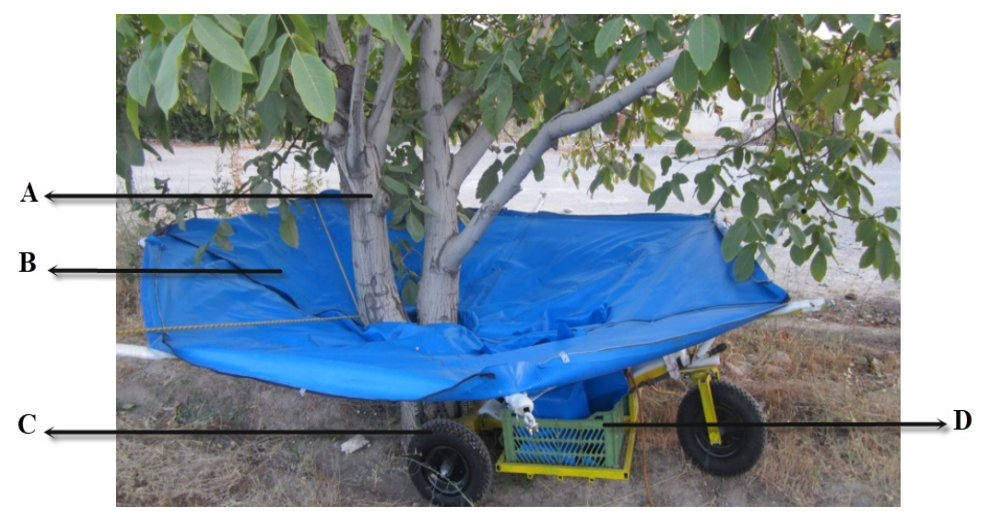

Figure 8. Collector system parts. (A) Tree trunk. (B) Polyester cover. (C) Wheels. (D) Box.

\subsection{Evaluation Criteria of Harvester}

The oily type of olive was used for evaluation. Tests were conducted in the Ashrafieh garden in Qazvin province in Iran, and the fruit ripening index was $4.52 \%$. The age of olive trees was 20 years, and the height of trees was up to $3.5 \mathrm{~m}$. The variance analysis was done in randomized complete block design, and the statistical computations as well as the data analysis were performed by the MSTAT-C software. Duncan's multi-scope test was used for comparison of the means.

The performance of the developed harvest machine was measured by the harvesting productivity (HP), harvesting efficiency (HE), and leaves downfall percentage (LD). The performance of the developed collector system was measured by the olive fruit damage (FD). For measuring the harvesting productivity of olive fruit harvester, the total mass of detachment fruits was recorded using the machine. The total harvesting time includes selecting fruit, detaching fruit, and the time required for moving machine between olive trees inside the field. The productivity of the operated harvester was calculated using Equation (10) [34]:

$$
H P=\frac{k_{1}}{T}
$$

Harvesting efficiency was calculated by Equation (11) [35]:

$$
H E=\frac{K_{1}}{K_{2}+K_{1}} \times 100
$$

The percentage of olive leaves downfall is defined as the percentage of branches and leaves felled by the harvester and was calculated by Equation (12):

$$
T D=\frac{M_{b l}}{M_{t b l}} \times 100
$$

Fruit damage is determined by visual inspection of whether the fruit appears broken to the naked eye. Fruit damage was calculated by Equation (13):

$$
F D=\frac{M_{d}}{M_{t}} \times 100
$$

\subsection{Solar Dryer System}

In the present study, an indirect solar dryer system using a dish concentrator with a cylindrical cavity receiver was experimentally built and tested. The solar dryer system was composed of different parts, including a dish concentrator with a cylindrical cavity receiver, a dryer system for drying mint by blowing hot air from a heat exchanger, a tank for reserving solar working fluid, and a pump for circulating solar working fluid. Figure 9 is an illustration of the different parts of the experimental setup. It is worth mentioning 
that that pure thermal oil and $\mathrm{Al}_{2} \mathrm{O}_{3}$ /thermal oil nanofluid were used as the solar working fluid. Initially, the solar working fluid was circulated in the cavity receiver in order to absorb the solar energy. Afterwards, the heated solar working fluid was entered into the dryer heat exchanger in order to transfer the absorbed solar energy to the blowing air in the dryer system for drying mint. Subsequently, the solar working fluid was reserved in a tank for saving absorbed energy in the night-time or during cloudy weather. Ultimately, the pump was providing circulation of the solar working fluid in the system for absorbing solar energy in the cavity receiver and drying plants in the dryer system. The following section deals with demonstration of the different mentioned parts of the solar dryer system.

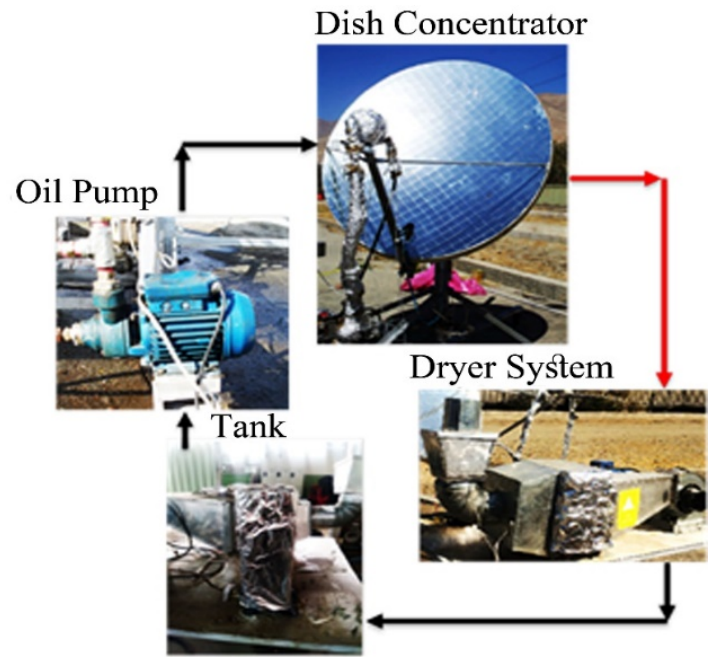

Figure 9. A view of different parts of the experimental setup.

\subsubsection{Solar Collector and Dryer}

The solar dish concentrator with a cylindrical cavity receiver was taken into consideration as a heat source of the indirect dryer system. Structural dimensions of the cylindrical cavity receiver were selected based on an optimization study by the authors in the previous paper [15]. Table 4 represents the dimensions of the dish concentrator and cavity receiver. The application of the solar dish concentrator with the cylindrical cavity receiver was changed from a heat source of a power generation system in the previous publications to the dryer heat source in the current research. Furthermore, the performance of the system was experimentally evaluated in this research. Figure 10 shows the solar dish concentrator with the cavity receiver.

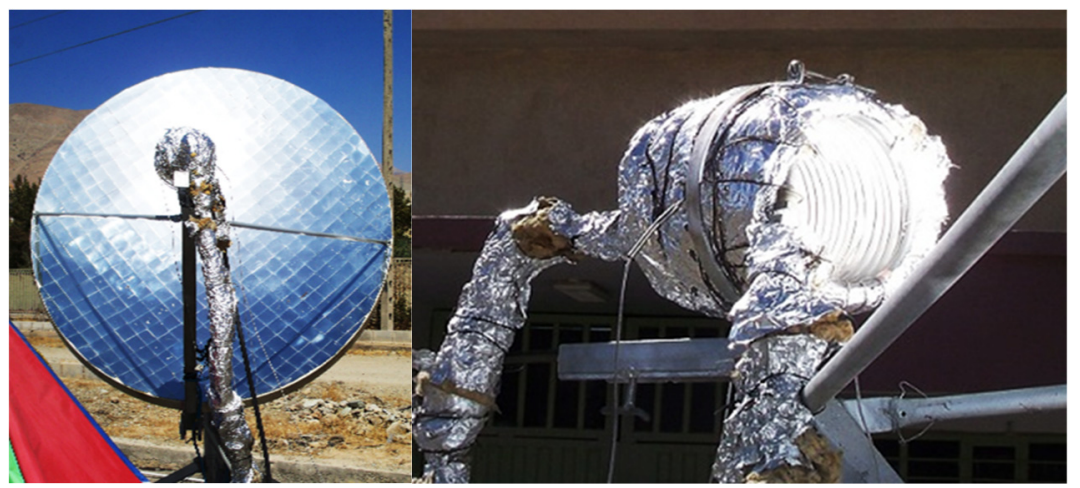

(a)

(b)

Figure 10. A view of the solar system: (a) the dish concentrator, and (b) the cylindrical cavity receiver. 
Table 4. The specification of the dish concentrator and cylindrical cavity receiver.

\begin{tabular}{|c|c|}
\hline Structural Dimensions & Values \\
\hline \multicolumn{2}{|c|}{ Dish Concentrator } \\
\hline Aperture diameter & $2 \mathrm{~m}$ \\
\hline Focal length & $0.693 \mathrm{~m}$ \\
\hline Reflectance & 0.84 \\
\hline Tracking error & $1^{\circ}$ \\
\hline Rim angle & $45^{\circ}$ \\
\hline Concentration ratio & 165 \\
\hline Focal length & $0.693 \mathrm{~m}$ \\
\hline \multicolumn{2}{|c|}{ Cylindrical Cavity Receiver } \\
\hline Outer diameter & $16 \mathrm{~cm}$ \\
\hline Inner diameter & $14 \mathrm{~cm}$ \\
\hline Height & $14 \mathrm{~cm}$ \\
\hline Number of tube turns at the cavity height & 14 \\
\hline Diameter of the cavity inner tube & $10 \mathrm{~mm}$ \\
\hline
\end{tabular}

Another part of the indirect solar dryer system is the dryer system. Figure 11 deals with the different parts of the solar dryer. The dryer system is composed of a fan for blowing air, a heat exchanger for transferring thermal energy from the solar working fluid to air, and a dryer compartment for carrying mint. The forced convection was used to pass the hot mass of air from the heat exchanger into the drying compartment. According to the previously reported papers, it was found that the highest required energy for mint drying is $60^{\circ} \mathrm{C}$. The designed dryer system was assumed to be a thin-layer system with olive fruit depth of $5 \mathrm{~cm}$. The weight of the sample for each experimental test was assumed equal to 50 gr. Dimensions of the dryer compartment were calculated with a length of $12 \mathrm{~cm}$ and width of $12.5 \mathrm{~cm}$. A heat exchanger was used for transferring absorbed heat from the solar working fluid to the air for drying, with a cross-section of $33 \times 34 \mathrm{~cm}^{2}$ and copper tube length of $0.33 \mathrm{~m}$ with the triangular arrangement.

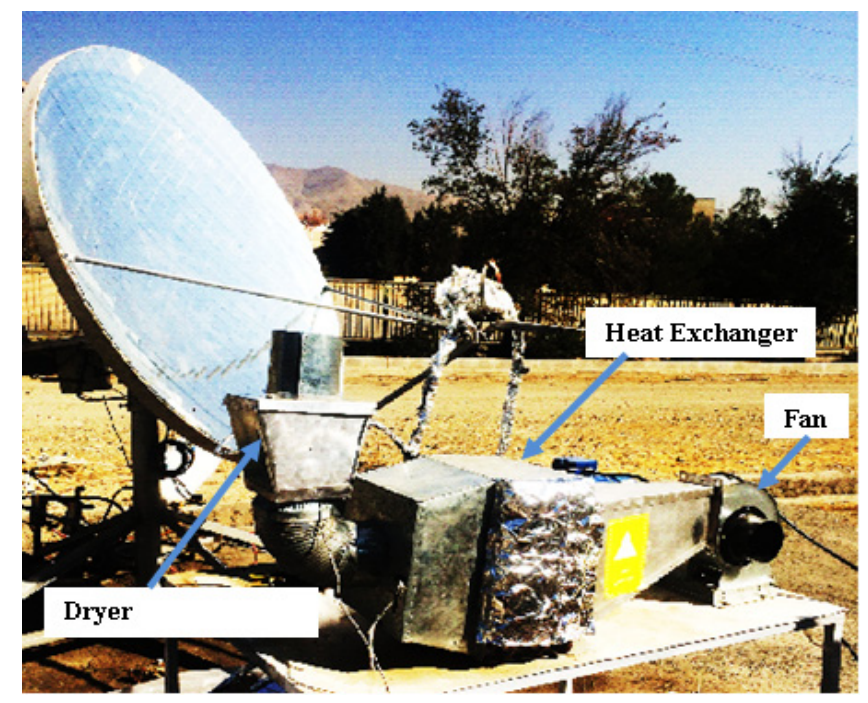

Figure 11. The solar dryer system.

Various operational and environmental parameters were measured during the experimental tests. The measured operational parameters included the following: (1) solar 
radiation, (2) wind speed, and (3) ambient temperature. The solar radiation was measured using Hukseflux Pyranometer, model SR12. The ambient temperature and wind speed were measured using a PT-100 sensor and anemometer CT model AM-4220, respectively. Nevertheless, the measured conditional parameters were categorized by the following: (1) air mass flow rate, (2) inlet and outlet temperatures of the solar working fluid for the cavity receiver and heat exchanger, and (3) inlet and outlet temperatures of air at the dryer compartment. The air mass flow rate was measured using a graduated cylinder, and the temperatures of the solar working fluid and air in the dryer system were measured using PT-100 sensors. Table 5 is a demonstration of accuracy and ranges of the measuring instruments.

Table 5. Accuracies and ranges of the measuring instruments.

\begin{tabular}{ccccc}
\hline S1. no. & Instrument & Accuracy & Range & \% Error \\
\hline 1 & PT-100 sensor & $\pm 1.35{ }^{\circ} \mathrm{C}$ & $-200-400{ }^{\circ} \mathrm{C}$ & 0.25 \\
2 & Solar power meter & $\pm 0.1 \mathrm{~W} / \mathrm{m}^{2}$ & $0-2000 \mathrm{~W} / \mathrm{m}^{2}$ & 0.25 \\
3 & Anemometer & $\pm 0.2 \mathrm{~m} / \mathrm{s}$ & 0.9 to $35.0 \mathrm{~m} / \mathrm{s}$ & 10 \\
\hline
\end{tabular}

\subsubsection{Nanofluid Preparation}

In the present study, the $\mathrm{Al}_{2} \mathrm{O}_{3}$ /thermal oil nanofluid and pure oil were used as the solar working fluid. The alumina nanoparticles (gamma, 99\%, 30-40 nm) were provided by the US Research Nanomaterial Company in American. Figure 12 presents a TEM picture of the alumina nanoparticles. It is worth mentioning that Behran thermal oil was used as the base fluid [36].

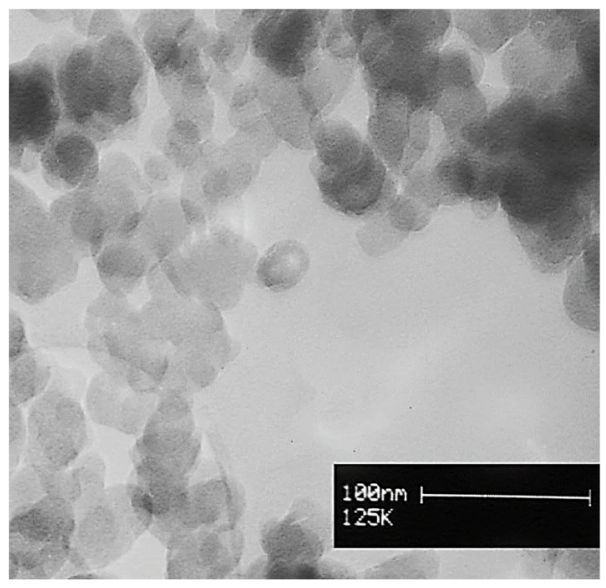

Figure 12. A TEM picture of the alumina nanoparticles.

For the purpose of the nanofluid preparation, the specified quantity of nanoparticles was first weighted based on the $0.8 \%$ mass fraction of nanoparticles using the following equation:

$$
\varphi_{P}=\frac{m_{P} \times 100}{m_{P}+m_{o i l}}=\frac{m_{P} \times 100}{m_{P}+\left(\rho_{o i l} V_{o i l}\right)}
$$

In this equation, $\varphi_{p}$ is nanofluid volume fraction, $m_{P}(\mathrm{~kg})$ is the nanoparticle mass, $m_{\text {oil }}(\mathrm{kg})$ is thermal oil mass, $\rho_{\text {oil }}\left(\mathrm{kg} / \mathrm{m}^{3}\right)$ is the density of the thermal oil, and $V_{\text {oil }}\left(\mathrm{m}^{3}\right)$ is the volume of the thermal oil. Based on this equation, for the specified volume of the thermal oil and nanofluid mass flow rate, a calculation was made on the quantity of nanoparticles. Then, the specified quantity of the nanoparticles was slowly added to the thermal oil. Later on, the suspension was well stirred by a stirrer at $400 \mathrm{rpm}$ and $150{ }^{\circ} \mathrm{C}$ for one hour to separate the particle agglomerations. Ultimately, the prepared suspensions were inserted in an ultrasonic system for about 15 min with a power of $100 \mathrm{~W}$ to break down the agglomeration between nanoparticles. A view of the preparing of $\mathrm{Al}_{2} \mathrm{O}_{3} /$ thermal 
oil nanofluid using the stirrer device and the ultrasonic system which was used from Tehran University, Tehran, Iran, is displayed in Figure 13a,b.

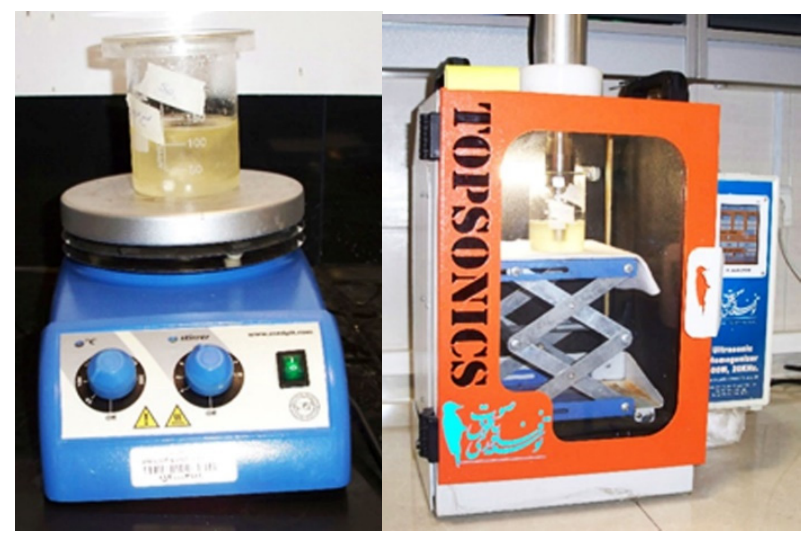

(a)

(b)

Figure 13. A view of the preparing of $\mathrm{Al}_{2} \mathrm{O}_{3}$ /thermal oil nanofluid using (a) the stirrer device and (b) the ultrasonic system.

On the other hand, the thermal properties of the alumina/thermal oil nanofluid were calculated based on the experimental relationships reported by Ref. [37] for the alumina/thermal oil nanofluid [38]. In a nutshell and based on the afore-mentioned statements, it can be argued that the selected nanofluid is a typical one according to the existing literature. $\mathrm{Al}_{2} \mathrm{O}_{3}$ is a common nanoparticle that has been used in numerous cases. The selected concentration is $0.8 \%$, which is enough for performance enhancement but not so high as to have agglomeration issues and high cost. The nanoparticle diameters are about 30-40 nm, which are typical values. Generally, it can be demonstrated that higher nanoparticle concentration and lower nanoparticle diameters usually result in higher thermal performance and higher pressure drop.

\subsubsection{Dryer Performance Evaluation}

As illustrated in the previous sections, mint plant was selected for drying in this study. For each test, $50 \mathrm{gr}$ of mint was provided from a farm near to the laboratory location. The prepared samples were located in a refrigerator at a temperature of $4{ }^{\circ} \mathrm{C}$. During the experimental tests, initial moisture content was estimated based on the ASABE S358.2 (2010) method. Based on this method, $100 \mathrm{gr}$ of mints were located in an oven for $24 \mathrm{~h}$ at $100{ }^{\circ} \mathrm{C}$. Reduction in moisture content was recorded by measuring weight of the samples during the drying process using an electronic balance with capacity of $1 \mathrm{~kg}$ and resolution of \pm 0.01 gr. The moisture content was calculated on wet bases as follows:

$$
M_{t}=\left(\frac{w_{w}-w_{d}}{w_{w}}\right) \times 100
$$

where, $M_{t}$ is moisture content on wet bases, $w_{w}$ (gr) is the weight of the wet sample, and $w_{d}(\mathrm{gr})$ is the weight of the dry sample. Experiments were conducted at three levels of inlet air temperature, including $40^{\circ} \mathrm{C}, 50^{\circ} \mathrm{C}$, and $60^{\circ} \mathrm{C}$, as well as three levels of inlet air speed, including $0.5 \mathrm{~m} / \mathrm{s}, 1 \mathrm{~m} / \mathrm{s}$, and $1.5 \mathrm{~m} / \mathrm{s}$. All of the tests were performed based on three repeats. Consequently, 27 tests were predicted for investigation of all of the parameters based on three repeats. It is worth mentioning that $\mathrm{Al}_{2} \mathrm{O}_{3}$ / oil nanofluid was used as the solar working fluid for all of the tests in this section. Temperature and speed of air were adjusted using an inventor system for variation in air speed with and a flow meter for variation in the nanofluid as solar working fluid. It should be stated that drying processes were conducted in the steady-state condition. 


\section{Results and Discussion}

\subsection{Physical and Mechanical Properties}

Table 6 shows the average moisture content, length, width, height, geometric mean diameter, arithmetic mean diameter, mass, sphericity, sample volume, true density, physical density, and porosity of the yellow olive cultivar. These cultivars were used to draw the olive fruit in software and to simulate it. The static friction coefficient for olives was obtained on three levels of galvanized sheet, steel sheet, and wood. Table 7 shows the static friction coefficient values.

Table 6. Physical properties of olive fruit.

\begin{tabular}{cc}
\hline Physical Properties & Amount \\
\hline Moisture percentage $(\%)$ & 64.93 \\
\hline Length $(\mathrm{mm})$ & $1.11 \pm 21.86$ \\
\hline Width $(\mathrm{mm})$ & $0.904 \pm 17.48$ \\
\hline Thickness $(\mathrm{mm})$ & $0.742 \pm 16.5$ \\
\hline Geometric mean diameter $(\mathrm{mm})$ & $0.846 \pm 18.47$ \\
\hline Arithmetic mean diameter $(\mathrm{mm})$ & $0.845 \pm 18.62$ \\
\hline Stalk diameter $(\mathrm{mm})$ & $1.89 \pm 0.85$ \\
\hline Sample mass $(\mathrm{gr})$ & $0.478 \pm 3.6$ \\
\hline Sphericity $\left(\mathrm{mm}^{3}\right)$ & $84 \pm 1.9$ \\
\hline Sample volume $\left(\mathrm{mm}^{3}\right)$ & $3.37 \pm 0.408$ \\
\hline True density $\left(\frac{\mathrm{kg}^{3}}{\mathrm{~m}^{3}}\right)$ & $1046.21 \pm 9.61$ \\
\hline Physical special density $\left(\frac{\mathrm{kg}}{\mathrm{m}^{3}}\right)$ & $3.24 \pm 537.7$ \\
\hline Porosity $(\%)$ & $0.473 \pm 48.6$ \\
\hline
\end{tabular}

Table 7. Static friction coefficient.

\begin{tabular}{cccc}
\hline & Galvanized & Steel & Wood \\
\hline Static friction coefficient & 25 & 17.75 & 19.75 \\
\hline
\end{tabular}

For the simulation purpose, the values of the obtained force need to be converted to stress. To this end, the average force of separation of the fruit from the branch was obtained, and the mean stress value was obtained based on the mean diameter of the stalk. Table 8 shows the values of the mechanical properties obtained.

Table 8. Mechanical properties of olive fruit.

\begin{tabular}{ccccc}
\hline Cultivar & Toughness $\left(\frac{\mathbf{M J}}{\mathbf{m}^{3}}\right)$ & $\begin{array}{c}\text { Failure Energy } \\
(\mathbf{J})\end{array}$ & $\begin{array}{c}\text { Failure Force } \\
(\mathbf{N})\end{array}$ & $\begin{array}{c}\text { Failure Stress } \\
(\mathbf{M P a})\end{array}$ \\
\hline Yellow & $0.072 \pm 0.07$ & $0.256 \pm 0.03$ & $22.53 \pm 8.7$ & \pm 2.4 \\
\hline
\end{tabular}

\subsection{Simulation}

Having performed a number of simulations, the outcomes revealed that the stress at two points of the olive is very important. The first point of stress is at the junction of the stalk with the fruit, and the second point is the point of finger contact with the olive fruit. The greater the amount of stress at the junction of the stalk, the greater the probability of detachment from the branch and falling. Excessive stress at the point of contact of the jaw with the olive will damage the olive fruit. Accordingly, the worst position of the olive relative to the jaw of the device is the position where the stress at the connection to the stalk 
is low. In other words, in the intensity of the same impact of the jaw on the olive fruit, the position in which the stress is lower in this area is selected as the basis for determining the minimum angular velocity of the jaw. In this regard, the effect of the position of the olive on the jaw of the harvesting machine was investigated, and the simulation results show that in the case where the olive is between the two jaws and the contact angles between the fruit, the finger of the jaw, and the angle formed with the jaw are $45^{\circ}$ and $0^{\circ}$, the amount of stress applied to the location of the fruit stalk is lower than in other cases. Figure 14 shows the simulation results of the jaw impact on the olive fruit in different positions of the olive relative to the jaw.

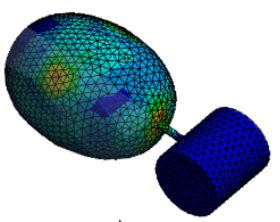

A.

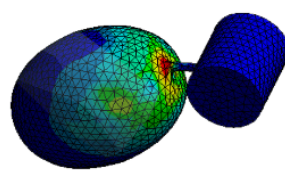

B.

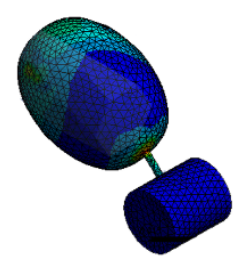

C.<smiles>C=CC=[SiH2]</smiles>

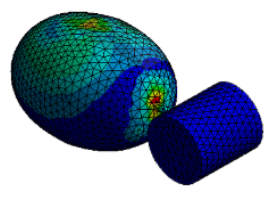

D.

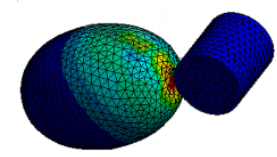

E.

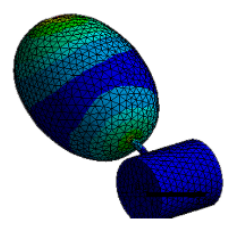

F.

number

contact angle (degree) placement angle (degree) Stress distribution color

\begin{tabular}{|c|c|c|c|}
\hline $\mathrm{A}$ & 45 & 0 & 9.3522e 7 Max \\
\hline B & 45 & -45 & $8.3131 \mathrm{e} 7$ \\
\hline $\mathrm{C}$ & 45 & 45 & $7.2739 \mathrm{e} 7$ \\
\hline $\mathrm{D}$ & 90 & 0 & $6.2348 \mathrm{e} 7$ \\
\hline $\mathrm{E}$ & 90 & -45 & $5.1957 \mathrm{e} 7$ \\
\hline \multirow{3}{*}{$\mathrm{F}$} & \multirow{3}{*}{90} & \multirow{3}{*}{45} & $3.1174 \mathrm{e} 7$ \\
\hline & & & $2.0783 \mathrm{e} 7$ \\
\hline & & & 1.0391e 7 \\
\hline
\end{tabular}

Figure 14. Simulation results of the jaw impact on the olive fruit in different positions of the olive relative to the jaw. Stress for A: Contact angle $45^{\circ}$ \& placement angle $0^{\circ}$; B: Contact angle $45^{\circ} \&$ placement angle $-45^{\circ} ; \mathrm{C}$ : Contact angle $45^{\circ}$ \& placement angle $45^{\circ} ; \mathrm{D}$ : Contact angle $90^{\circ}$ \& placement angle $0^{\circ}$; E: Contact angle $90^{\circ} \&$ placement angle $-45^{\circ}$; F: Contact angle $90^{\circ} \&$ placement angle $45^{\circ}$.

In Figure 14, Section A of the olive fruit is located between the fingers, both fingers hit the olive at the same time, and the stress distribution is symmetrically displayed on the other side of the olive. In this case, the contact angle and the placement angle are $45^{\circ}$ and $0^{\circ}$, respectively. The maximum stresses applied to the fruit at the point of contact with the jaw and at the point of attachment to the stalk in this case were 0.578 and $0.715 \mathrm{MPa}$, respectively. In Section B of Figure 14, the contact angle and the placement angle are 45 and -45 , respectively. The greater stress at the point of attachment to the stalk, compared to the 
stress at the point of finger contact with the fruit, is quite evident, and these stresses are equal to $1.06 \mathrm{MPa}$ and $0.707 \mathrm{MPa}$, respectively.

In Section C of Figure 14, the contact angle is $45^{\circ}$, and the placement angle is $45^{\circ}$. In this case, the stress at the junction with the stalk is more than the stress at the jaw collision with the fruit, which are equal to $0.918 \mathrm{MPa}$ and $0.712 \mathrm{MPa}$, respectively. The $\mathrm{D}, \mathrm{E}$, and $\mathrm{F}$ sections are related to the contact angle of $90^{\circ}$ and the placement of $0^{\circ},-45^{\circ}$, and $+45^{\circ}$. Only one finger hits the fruit in these three cases, and the difference in stress distribution with the $\mathrm{A}, \mathrm{B}$, and $\mathrm{C}$ sections is obvious. The stresses applied to the fruit in sections $\mathrm{D}$, $\mathrm{E}$, and $\mathrm{F}$ were $0.845 \mathrm{MPa}, 0.798 \mathrm{MPa}$, and $0.892 \mathrm{MPa}$, respectively, and the stresses at the point of attachment to the stalk were $0.810 \mathrm{MPa}, 1.03 \mathrm{MPa}$, and $0.801 \mathrm{MPa}$, respectively. Figure 15 shows a comparison between the maximum stress applied to the olive fruit at the two points of finger contact with the fruit and the point of attachment to the stalk.

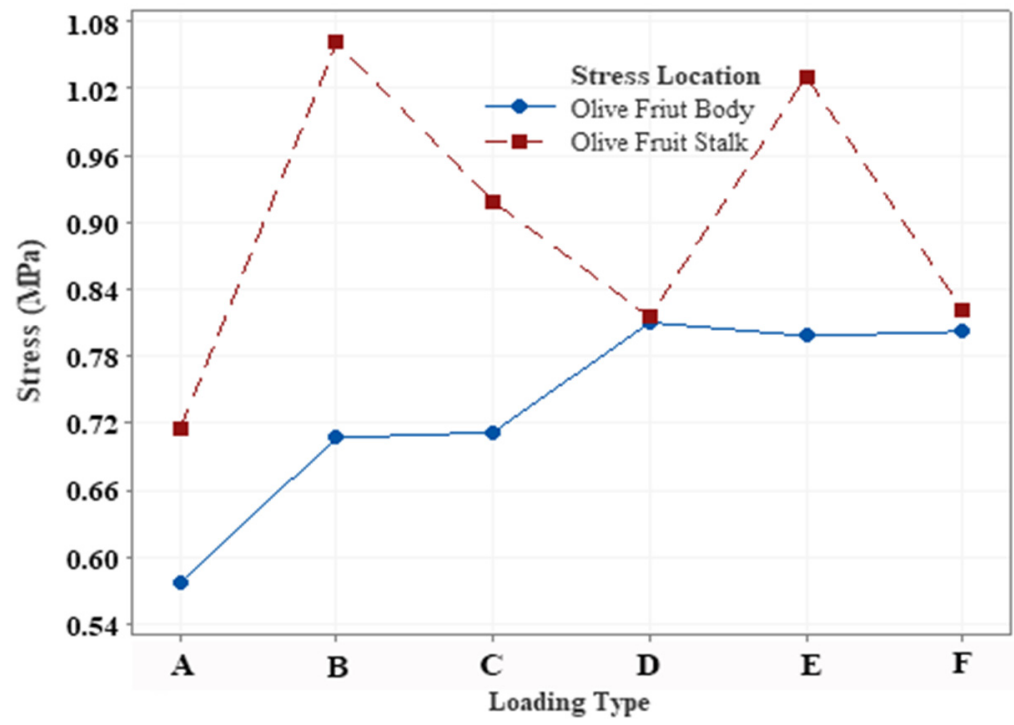

Figure 15. Comparison between the maximum stress applied to the olive fruit at the two points of finger contact with the fruit and the point of attachment to the stalk.

As Figure 15 shows, the least stress is applied to the fruit stalk by type A loading, so the type A loading model will be used to determine the minimum speed for separating the fruit from the branch.

To find the minimum rotational speed for separation of olive fruit from the branch, the effect of eight rotational speeds from 3.5 to 9.5 with 1 radian per second step on separation was investigated. Figure 16 represents the distribution of stress applied to the olive at different rotational speeds. Up to a rotational speed of 6.5 radians per second, the stresses applied to the junction with the stalk do not lead to failure, and the fruit is not separated from the branch. From a rotational speed of 7.5 radians per second to 9.5 radians per second, the stress applied to the junction with the olive fruit stalk leads to failure stress, and the fruit separates from the branch. Therefore, this amount of speed was used to design the olive harvesting machine. Figure 17 illustrates the trend of increasing stress in the olive fruit with increasing rotational speed of the jaw. The red area shows the stress range, and the white area shows the stress in the safe range. From a rotational speed of 6.5 radians per second, the stress in the area of connection to the stalk leads to failure stress, and the fruit separates from the branch. At this speed, the stress on the olive fruit is in the safe range, and after separating from the branch, bruising and serious damage to the fruit will not occur. 
9.3522e7 Max

$8.3131 \mathrm{e} 7$

$7.2739 \mathrm{e} 7$

$6.2348 \mathrm{e} 7$

$5.1957 \mathrm{e} 7$

$4.1565 \mathrm{e} 7$

$3.1174 \mathrm{e} 7$

$2.0783 \mathrm{e} 7$

$1.0391 \mathrm{e} 7$

0 Min

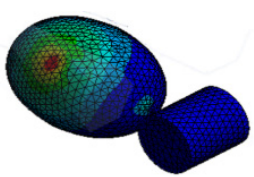

$\mathrm{V}=3.5 \mathrm{rad} . \mathrm{s}^{-1}$

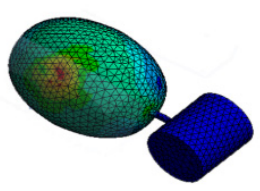

$\mathrm{V}=5.5 \mathrm{rad} . \mathrm{s}^{-1}$

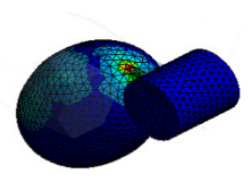

$\mathrm{V}=7.5 \mathrm{rad} . \mathrm{s}^{-1}$

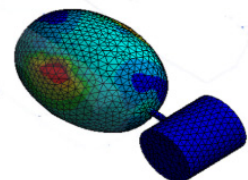

$\mathrm{V}=4.5 \mathrm{rad} . \mathrm{s}^{-1}$

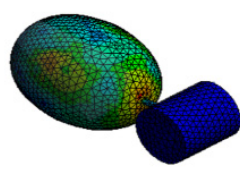

$\mathrm{V}=6.5 \mathrm{rad} . \mathrm{s}^{-1}$

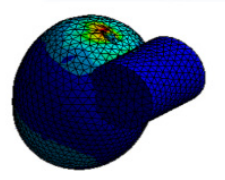

$\mathrm{V}=8.5 \mathrm{rad} . \mathrm{s}^{-1}$

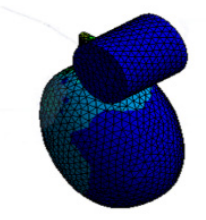

$\mathrm{V}=9.5 \mathrm{rad} . \mathrm{s}^{-1}$

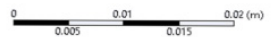

Figure 16. Distribution of stress applied to the olive at different rotational speeds.

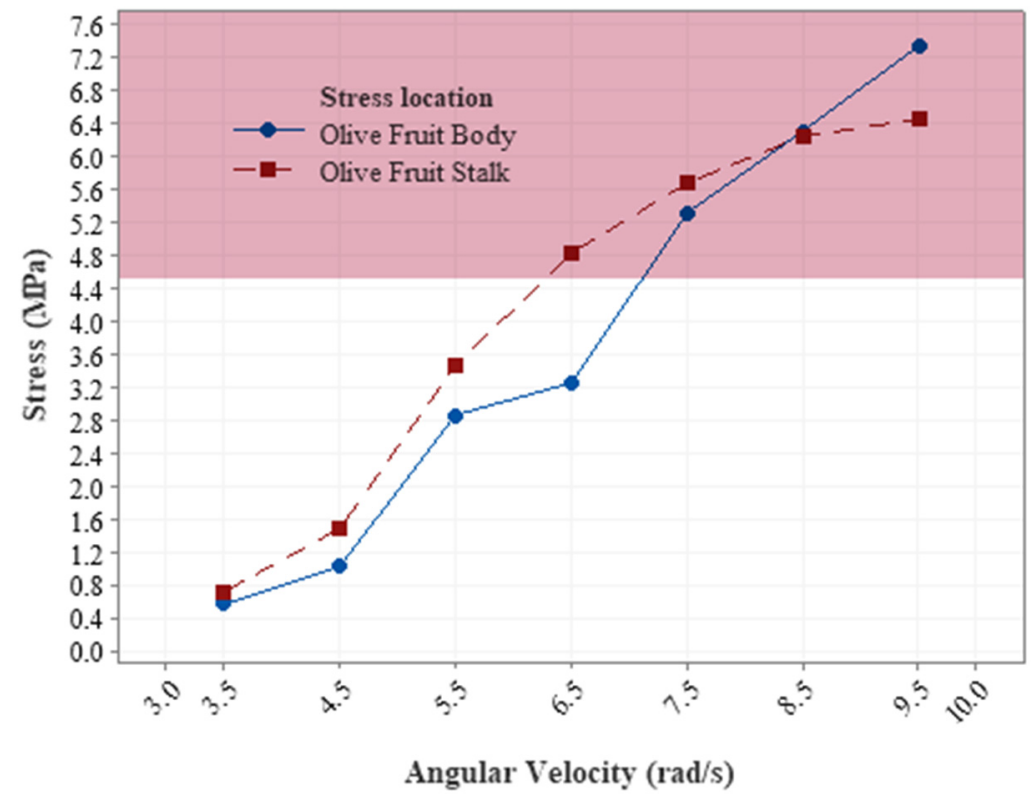

Figure 17. Effect of angular velocity on stress in the olive fruit body.

However, at the rotational speed of 6.5 radians per second, both the stresses at the junction with the stalk and the stress at the point of impact of the jaw finger with the fruit lead to the failure area, so in this case and at higher speeds, the rotational speed of the applied stress will damage the product and create permanent bruises. Obtaining the minimum frequency of damage to the olive fruit is effective when it comes to reducing the consumed energy of the harvesting machine. On the other hand, designing the olive harvesting machine prevents damage to the olive fruit while harvesting based on the 
minimum frequency of jaws. Therefore, simulation in these two contexts affected the designing.

\subsection{Harvesting Machine}

\subsubsection{Harvesting Productivity}

Harvesting productivity was calculated using Equation (10) and the results of variance analysis for harvesting productivity among three types of harvesters, including manual harvest $(\mathrm{MH})$, pneumatic harvester $(\mathrm{PH})$, and new pneumatic harvester $(\mathrm{NPH})($ machine of this study) are shown in Table 9. Results show that the three harvesters have a significant difference at $5 \%$ levels of probability. Due to different treatments, the means were compared, and the NPH was found to have more HP placed in a group (a) with an amount of $29.47 \mathrm{~kg} / \mathrm{h}$. The $\mathrm{PH}$ was placed in a group (b) with an amount of $21.33 \mathrm{~kg} / \mathrm{h}$, and the $\mathrm{MH}$ was placed in a group (c) with an amount of $9.37 \mathrm{~kg} / \mathrm{h}$.

Table 9. Result of variance analysis for HP.

\begin{tabular}{ccccc}
\hline Parameters & df & SST & MST & F \\
\hline Block & 2 & 34.925 & 17.462 & 1.6126 \\
Harvest method & 2 & 283.554 & 141.777 & 13.093 \\
Total & 4 & 43.314 & 10.828 & \\
\hline CV & $25 \%$ & & & \\
\hline
\end{tabular}

Figure 18 shows the HP means for three harvest methods. Due to the special properties of NPH, such as the power of vibration, frequency, and shape of a bar, the HP of this machine was greater when compared to two other methods of harvesting. Kermani (2016) indicated that the mounted branch-shaker machine has $130.72 \mathrm{~kg} / \mathrm{h}$ of HP, but it fails to be used in traditional gardens. This type of harvester needs a tractor to perform, which is not feasible for small gardens [39].

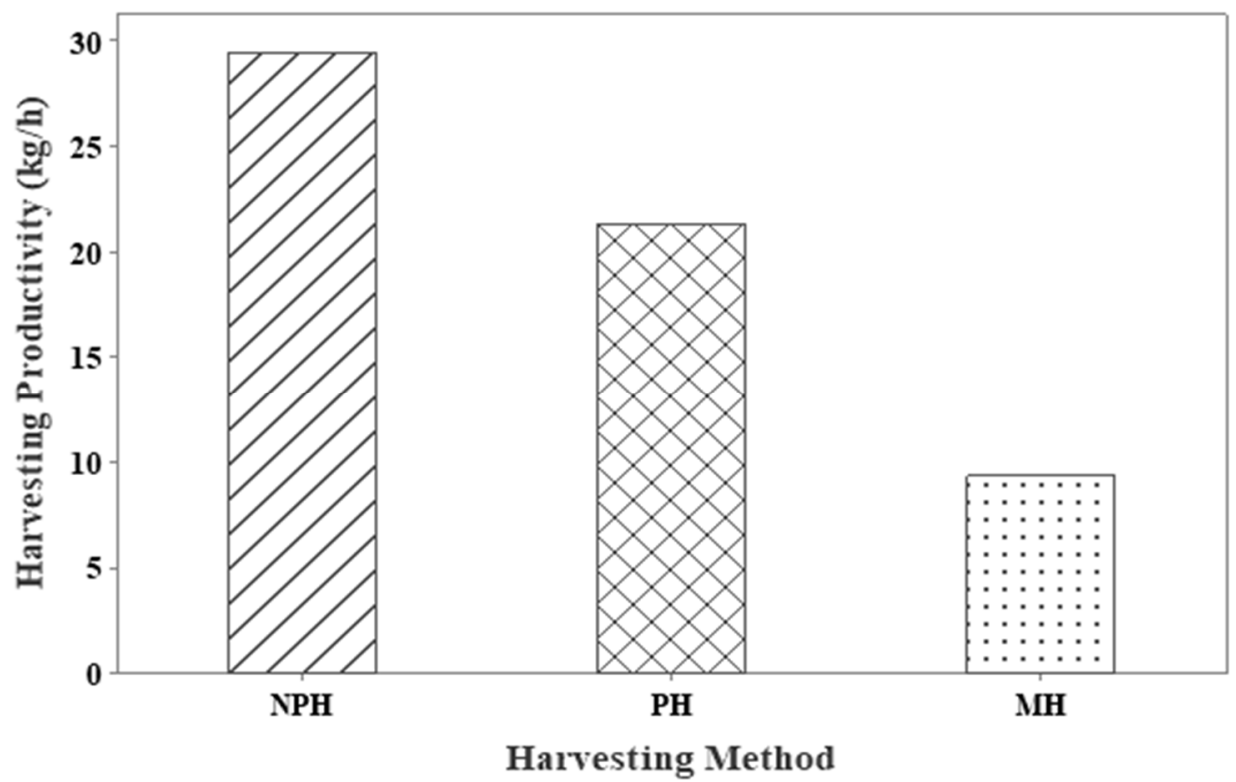

Figure 18. HP means for three harvesting methods.

\subsubsection{Harvesting Efficiency}

Table 10 shows the results of variance analysis related to the difference between two types of harvesting machine concerning harvesting efficiency (HE). The analysis shows that the effect of machine type on HE is significant at $1 \%$ probability. The pneumatic harvester can detach $86 \%$ of olives from the tree, but NPH shares $92 \%$ of HE. Because of 
the availability of all olives on the tree, the HE of this method is considered as $100 \%$ for labor in the case of manual harvest (Figure 19). It is very important to understand how to place the harvesting head on the telescoping rod. The angle between the harvester head and telescoping rod in the NPH is fixed, and the jaws move between 123 to 213 degrees. Such a property differs from the $\mathrm{PH}$. The other important difference resulting in increased HE is the jaws' speed, as they move quicker in NPH compared to the PH. Some locations of olive fruits on the tree are not available for NPH and $\mathrm{PH}$. The harvester rod plays an important role in the HE. The higher the harvester rod's maneuverability, the more olive fruits can be detected and the more the HE increases.

Table 10. Result of variance analysis of HE.

\begin{tabular}{ccccc}
\hline Parameters & df & SST & MST & F \\
\hline Between data & 1 & 717.883 & 717.838 & $118.644^{* *}$ \\
Inside data & 4 & 24.203 & 6.05 & \\
\hline CV & $3.25 \%$ & & \\
** $p$ values (A $p$-value is a measure of the probability that an observed difference could have occurred just by \\
random chance) less than 0.001.
\end{tabular}

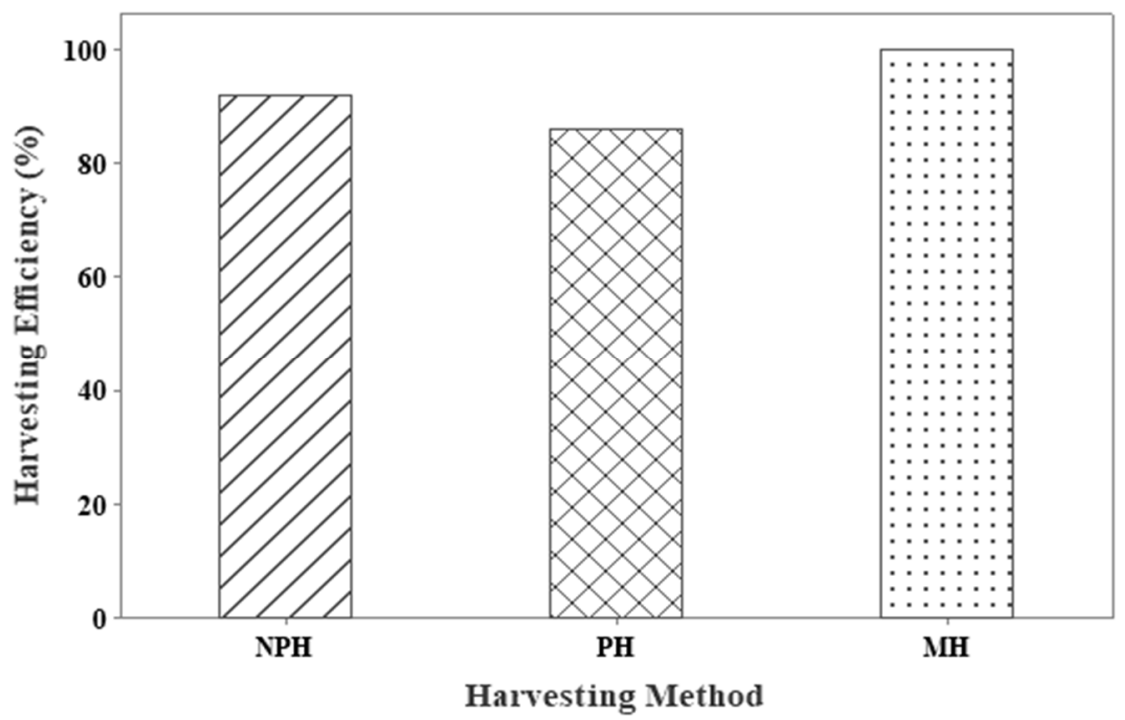

Figure 19. HE means for three harvesting methods.

The olive tree branch-shaker machine has $84.51 \% \mathrm{HE}$, but compared to other machines, the leaves downfall percentage in this harvesting method is high $[39,40]$.

\subsubsection{Leaves Downfall Percentage}

Equation (12) was used to determine leaves downfall percentage (LD). After harvesting, all the branches and leaves were collected and weighted. By increasing thebranches and leaves that fall from the tree, the LD was increased. Table 11 shows the variance analysis among the three harvesting methods and olive types. The effect of variety (type) on LD was not significant, but harvesting methods have a significant effect on LD. Figure 20 shows the LD for three harvesting methods; the new pneumatic harvester has more LD than the two other harvesting methods. The speed of jaws in the PH is 1080-1150 rpm, while in the NPH, the minimum speed of jaws is $1290 \mathrm{rpm}$. This difference in jaws speed led to an increase in the leaves downfall percentage. 
Table 11. Result of variance analysis for LD.

\begin{tabular}{ccccc}
\hline Parameters & df & SST & MST & F \\
\hline Block & 2 & 0.286 & 0.143 & 4.2503 \\
Harvest method & 2 & 1.006 & 0.503 & $14.934^{*}$ \\
Total & 4 & 0.135 & 0.034 & \\
\hline CV & $8.93 \%$ & & \\
* $p$ values (A $p$-value is a measure of the probability that an observed difference could have occurred just by \\
random chance) less than 0.05.
\end{tabular}

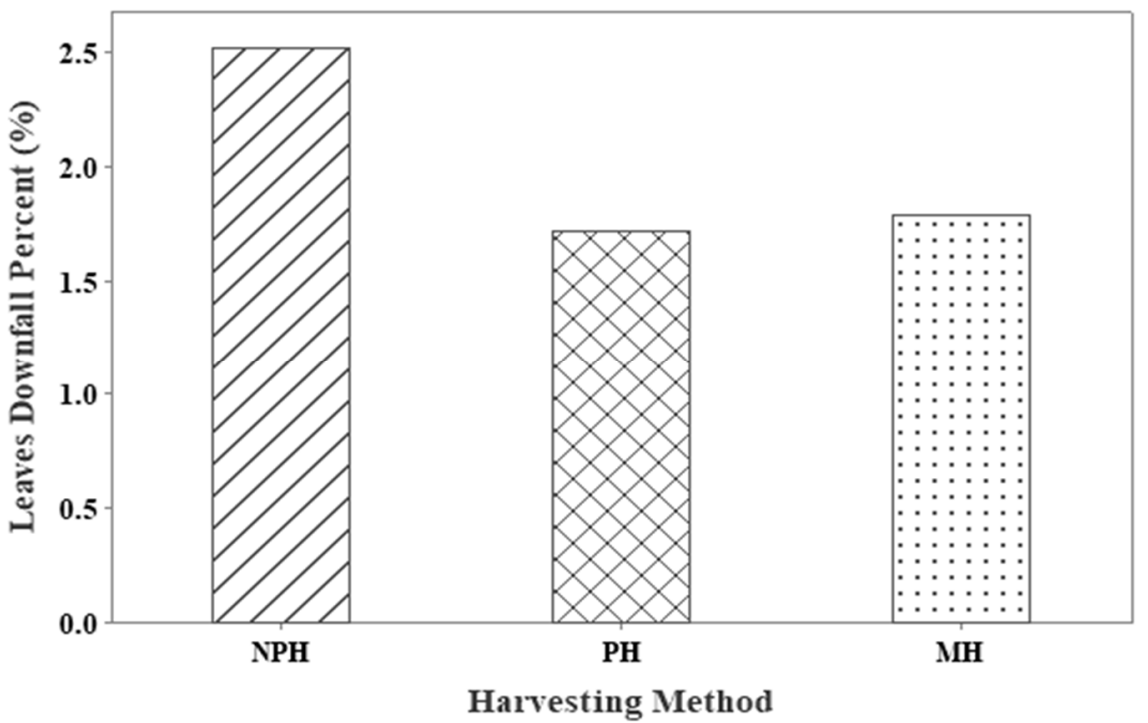

Figure 20. LD means for three harvesting methods.

Comparison of the means of harvesting method shows that the NPH, with an amount of $2.52 \% \mathrm{LD}$, has the highest detachment of leaves from the tree. The $\mathrm{PH}$ and $\mathrm{MH}$ were not significantly different, and they were placed in a group (b). The electrical rotation bar in Kermani's (2016) research has the highest LD, with 2.20\% damage [39]. Due to the problems with the head location on the handle in the NPH, the amount of LD was increased; however, such a problem can be surmounted.

\subsubsection{Collector System}

Olive fruits fall on the ground after harvesting and become damaged as a result of this matter. To protect the olive fruits from damage, a collector system gathering the fruits into the box was designed and manufactured. For evaluating the collector system, two types of olive trees were harvested with the new pneumatic harvester, and the percentages of damaged and undamaged olive fruits were investigated. Table 12 shows the damaged and undamaged olive fruit in the NPH with the collector systems and manual harvest without the collector system.

Table 12. Damaged and undamaged fruits with two types of harvesting method in Mari and yellow variety.

\begin{tabular}{ccccc}
\hline & \multicolumn{2}{c}{ MH } & \multicolumn{2}{c}{ NPH } \\
\hline & $\begin{array}{c}\text { Undamaged } \\
\text { Fruit (\%) }\end{array}$ & $\begin{array}{c}\text { Damaged Fruit } \\
(\mathbf{\%})\end{array}$ & $\begin{array}{c}\text { Undamaged } \\
\text { Fruit (\%) }\end{array}$ \\
\hline Mari & 39.2 & 60.8 & Mari & 39.2 \\
\hline yellow & 39.45 & 60.54 & yellow & 39.45 \\
\hline
\end{tabular}


Results show that the use of a collector system can decrease the fruit damage (FD) from $60.80 \%$ to $25.12 \%$ in the Mari variety. Similar results were achieved for the yellow variety. Table 6 shows the damaged and undamaged olive fruit for the harvesting of yellow olive fruit variety in the two harvesting methods. Figure 21 shows the injured, bruised, and uninjured olive fruit percentages in fourteen measured samples for the manual harvest. Due to the variation in the weight of olive fruits, the percentage of each group shown is based on the number and weight of olive fruits. In the manual harvest, a large portion of the olive fruits falls on the ground and is then picked up and collected into the box. This process led to the bruising of more than half of the olive fruits. Table 13 shows the means, standard deviation, average deviation, variance, minimum, and maximum of weight, along with the number of injured, bruised, and uninjured olive fruits in the manual harvest. Results show that after harvesting the fruits of the olive with the manual harvest method, $45.29 \%$ of olive fruits were bruised. Bruising occurred on the skin of the olive fruits as a result of fruit hitting the soil. Also, the injuring situation occurred when fruits were hit by sharp branches or stones.

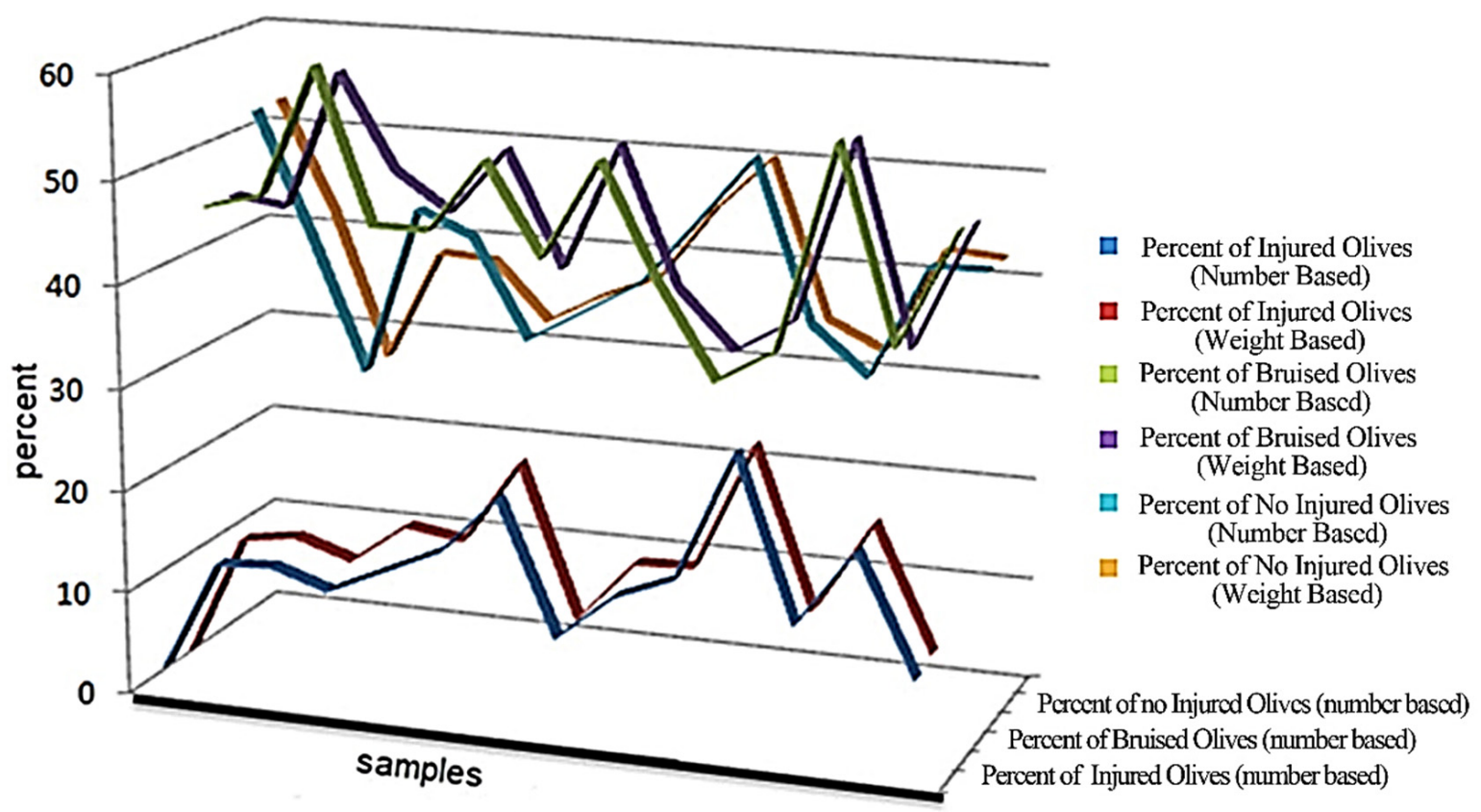

Figure 21. Illustration of the injured, bruised, and uninjured olive fruit in the manual harvest.

Table 13. Results of measuring the injury parameters for the olive fruits in the manual harvest.

\begin{tabular}{|c|c|c|c|c|c|c|}
\hline & $\begin{array}{c}\text { Number of } \\
\text { Injured Olives }\end{array}$ & $\begin{array}{c}\text { Weight of } \\
\text { Injured Olives }\end{array}$ & $\begin{array}{c}\text { Number of } \\
\text { Bruised Olives }\end{array}$ & $\begin{array}{c}\text { Weight of } \\
\text { Bruised Olives }\end{array}$ & $\begin{array}{c}\text { Number of } \\
\text { Uninjured } \\
\text { Olives }\end{array}$ & $\begin{array}{c}\text { Weight of } \\
\text { Uninjured } \\
\text { Olives }\end{array}$ \\
\hline Means & 14.87 & 15.51 & 45.42 & 45.29 & 39.71 & 39.20 \\
\hline $\begin{array}{l}\text { Standard } \\
\text { Deviation }\end{array}$ & 1.70 & 1.71 & 2.04 & 1.98 & 1.95 & 1.87 \\
\hline $\begin{array}{c}\text { Average } \\
\text { Deviation }\end{array}$ & 6.35 & 6.39 & 7.65 & 7.39 & 7.30 & 6.99 \\
\hline Variance & 40.37 & 40.89 & 58.52 & 54.67 & 53.29 & 48.93 \\
\hline Minimum & 2.52 & 2.31 & 32.28 & 33.84 & 27.07 & 27.26 \\
\hline Maximum & 28.97 & 28.18 & 59.40 & 57.87 & 52.46 & 52.60 \\
\hline
\end{tabular}


The percentages of injured, bruised, and uninjured olive fruits for NPH based on number and weight are shown in Figure 22. The results improved significantly. Most parts of the olive fruit had no injury in the harvesting process. Olive fruits that were detached from the tree fall in the collector systems and avoid contact with stones or the soil/ground. Table 14 shows the results of measuring related to the injured olive fruit parameters. The means of uninjured olive fruits in the NPH increased from $39.71 \%$ to $76.02 \%$. This means that the NPH was able to save almost half of the olive fruits. The jaws hit olive fruits and detached fruits from bunches; after that, fruits fell from the tree and collided with the branch and trunk of the tree. This process caused almost $24 \%$ damage to the olive fruits. $16 \%$ of the olive fruits in the harvesting process were bruised, and the rest of the damaged fruits had ruptured skin, which were then classified as injured fruits. Schema of the injured, bruised, and uninjured olive fruit in harvesting with NPH has been shown in Figure 22.

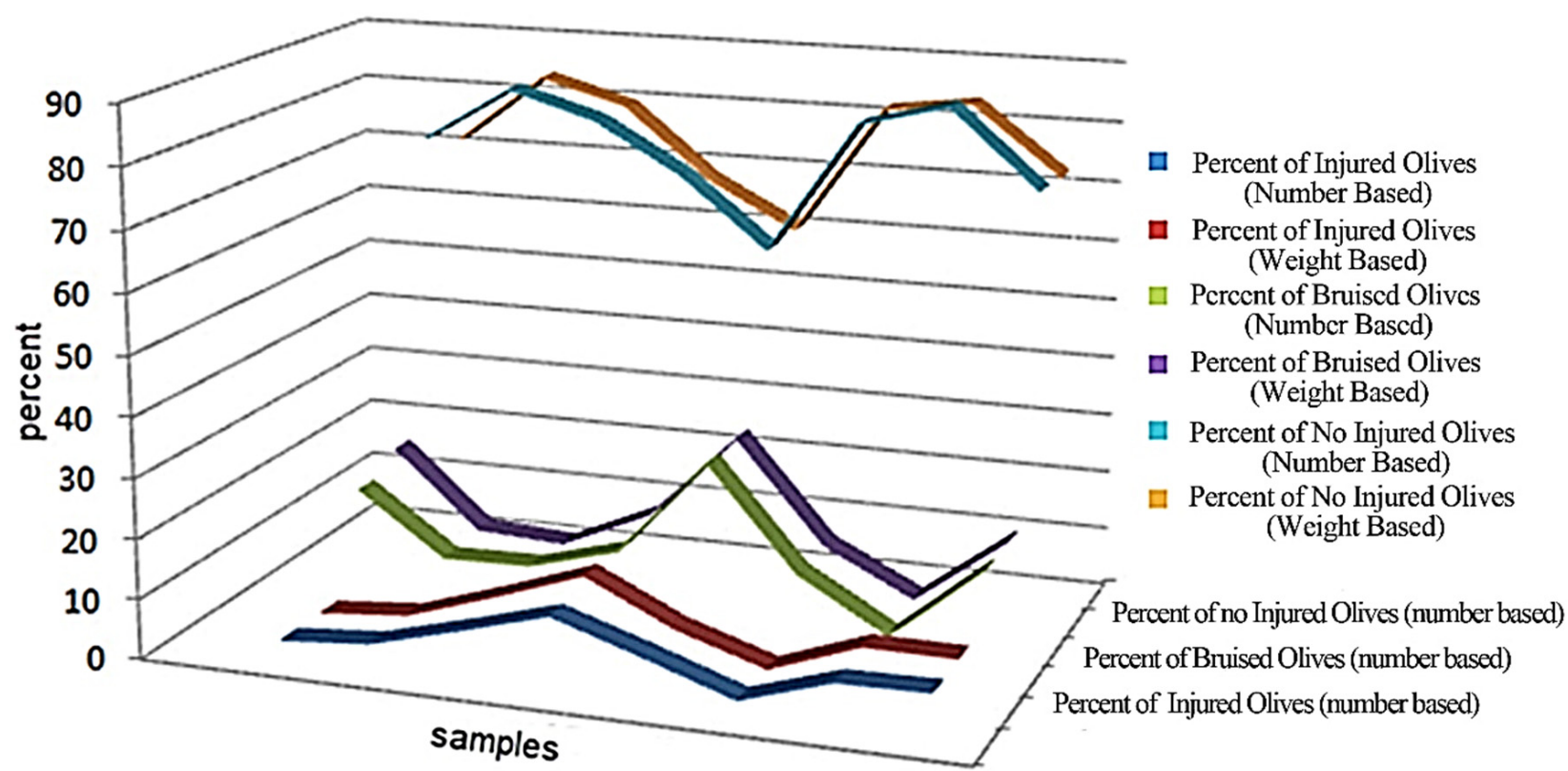

Figure 22. Schema of the injured, bruised, and uninjured olive fruit in harvesting with NPH.

Table 14. Result of measuring the injury parameters for the olive fruits in the case of harvesting with NPH.

\begin{tabular}{ccccccc}
\hline & $\begin{array}{c}\text { Number of } \\
\text { Injured Olives }\end{array}$ & $\begin{array}{c}\text { Weight of } \\
\text { Injured Olives }\end{array}$ & $\begin{array}{c}\text { Number of } \\
\text { Bruised Olives }\end{array}$ & $\begin{array}{c}\text { Weight of } \\
\text { Bruised Olives }\end{array}$ & $\begin{array}{c}\text { Number of } \\
\text { Uninjured } \\
\text { Olives }\end{array}$ & $\begin{array}{c}\text { Weight of } \\
\text { Uninjured } \\
\text { Olives }\end{array}$ \\
\hline Means & 7.98 & 8.33 & 15.98 & 16.79 & 76.02 & 74.88 \\
\hline $\begin{array}{c}\text { Standard } \\
\text { Deviation }\end{array}$ & 1.14 & 1.36 & 2.75 & 2.79 & 2.96 & 2.98 \\
\hline $\begin{array}{c}\text { Average } \\
\text { Deviation }\end{array}$ & 3.22 & 3.84 & 7.77 & 7.89 & 8.37 & 70.14 \\
\hline Variance & 10.34 & 14.78 & 60.34 & 62.29 & 7.41 & 59.70 \\
\hline Minimum & 3.88 & 3.80 & 6.03 & 31.44 & 85.34 & 60.02 \\
\hline Maximum & 13.75 & 15.61 & 31.34 & & 83.34 \\
\hline
\end{tabular}

\subsection{Solar Dish Performance}

The outcomes of the study concerning the cavity thermal performance using pure thermal oil and $\mathrm{Al}_{2} \mathrm{O}_{3}$ /thermal oil nanofluid as the solar working fluid were presented. In addition, representing different measured environmental and conditional parameters 
was attempted when considering the experimental tests. Experiments were led during the following times: 9:00 to 14:00 on 29 and 30 September 2020. It was observed throughout the experimental tests that the volume flow rate pertaining to the solar working fluids was $15 \mathrm{~mL} / \mathrm{s}$. Figure 23 is an illustration of an experimental day concerning the variations attributed to solar radiation, ambient temperature, and oil temperature difference as regards the inlet and outlet of the cavity receiver. The changes in solar radiation are presented in Figure 8 , where it varied from $958 \mathrm{~W} / \mathrm{m}^{2}$ at $12: 40$ to $631 \mathrm{~W} / \mathrm{m}^{2}$ at 9:00. It is worth pointing out that the variation in the ambient temperature was from $24{ }^{\circ} \mathrm{C}$ at $12: 40$ to $22{ }^{\circ} \mathrm{C}$ at 9:00. It can be inferred from Figure 23 that changes in conditions from $80{ }^{\circ} \mathrm{C}$ at $12: 40$ to $33{ }^{\circ} \mathrm{C}$ at 9:00 can be related to the oil difference temperature at the inlet and outlet of the cavity receiver. When compared to the changes in solar radiation, the difference in oil temperature at inlet and outlet of the cavity receiver follows a similar data trend.

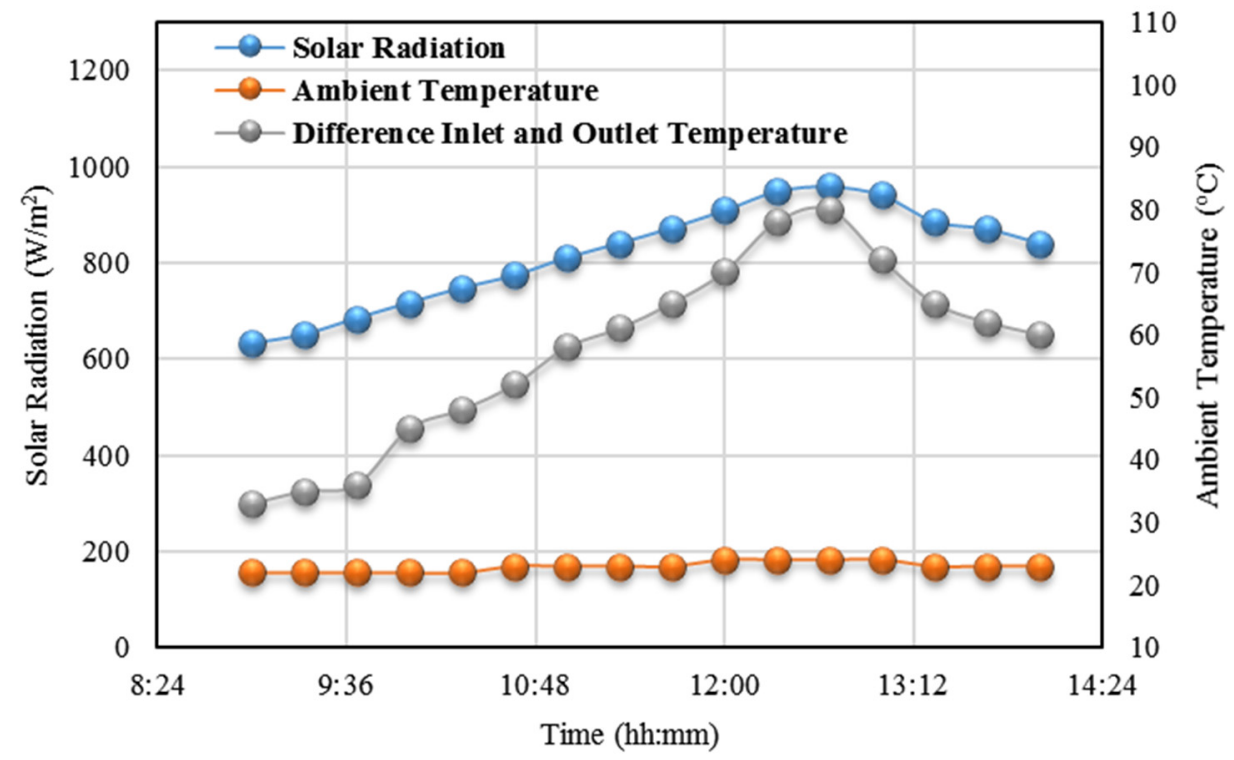

Figure 23. Variation in solar radiation, ambient temperature, and oil temperature difference at inlet and outlet of the cavity during the experimental day 29 September 2020, with thermal oil as working fluid.

Figure 24 is a depiction of the variations concerning the cavity top wall temperature, cavity sidewall temperature, and wind speed during the experimental test using the thermal oil as the solar working fluid. A range from $235^{\circ} \mathrm{C}$ at $12: 40$ to $186^{\circ} \mathrm{C}$ at 9:00 was noted regarding the cavity top wall temperature. In addition, the variation in the measured cavity sidewall temperature was reported from $185^{\circ} \mathrm{C}$ at $12: 40$ to $136{ }^{\circ} \mathrm{C}$ at 9:00 during the experimental test of the cylindrical cavity receiver, with the pure thermal oil as the solar working fluid. What was observed was the higher surface temperature compared to the cavity sidewall, which was obtained as the result of the cavity top wall. Such a finding is believed to be reasonable, since numerous solar rays accumulate in the top wall, and thereby the temperature increases in this region. Another observation was the variation in the wind speed, indicating a shift from $2 \mathrm{~m} / \mathrm{s}$ at 12:00 to 0 at 9:00 during the experimental test. Figure 24 illustrates the finding that the cavity surface temperatures yielded a comparable trend with the variation in the wind speed. Last but not least, a variation in cavity heat gain and thermal efficiency of the solar dish concentrator with the cylindrical cavity receiver, using thermal oil as the solar working fluid, during the experimental test on 29 September 2017 is shown in Figure 10. There is a variation of $2086 \mathrm{~W}$ at 12:40 to $858 \mathrm{~W}$ at 9:00, considering the cavity heat gains. Another result to be noted is the range change occurred (in 85\% context) in the thermal efficiency of the solar system, which is from 12:40 to $53 \%$ at 9:00. 


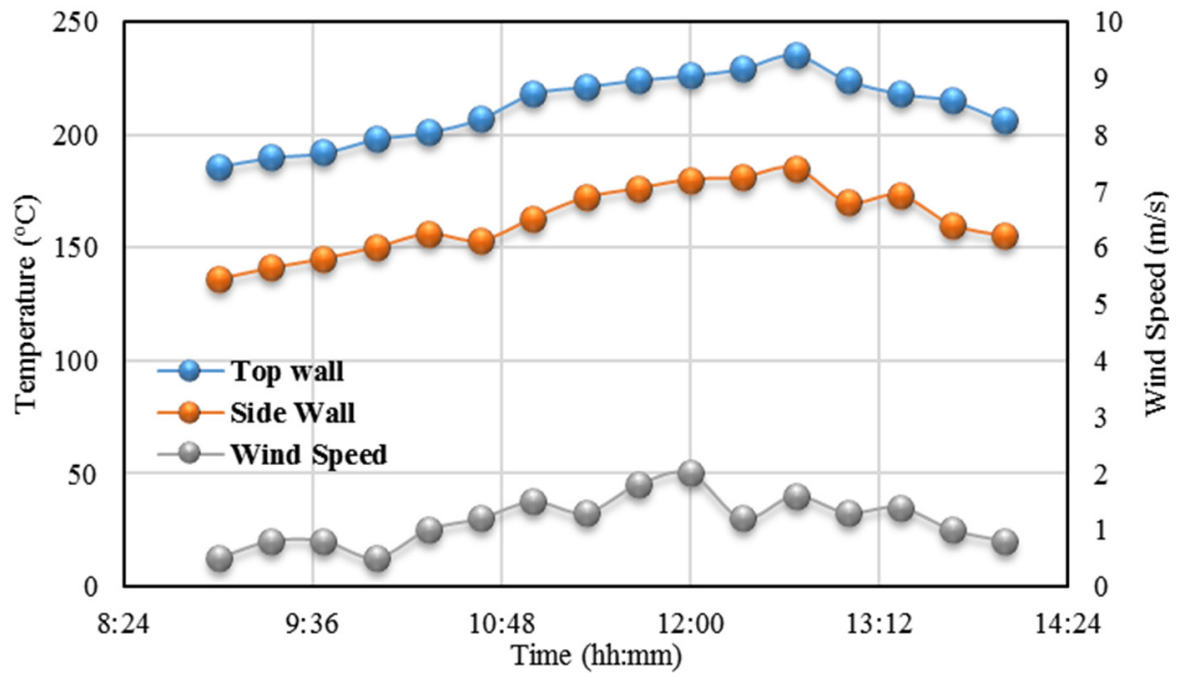

Figure 24. Variation in top wall temperature, sidewall temperature, and wind speed during the experimental day 29 September 2020, with thermal oil as the solar working fluid.

It can be inferred from Figure 25 that the cavity heat gains and thermal efficiency of the cavity receiver overlap in terms of the trend data, which is comparable to the oil temperature difference at the inlet and outlet of the cavity receiver. Another conclusion to be drawn is that the difference in the oil temperature at the inlet and outlet of the cavity receiver is taken into consideration as an effective parameter with regards to the thermal performance of the dish concentrator system with the cavity receiver. Ultimately, it can be stated considering the first operating hour in the morning that the system efficiency can be characterized as relatively low, since there is an absence of stable circumstances, and it is essential to warm up the system, which itself requires consideration of time.

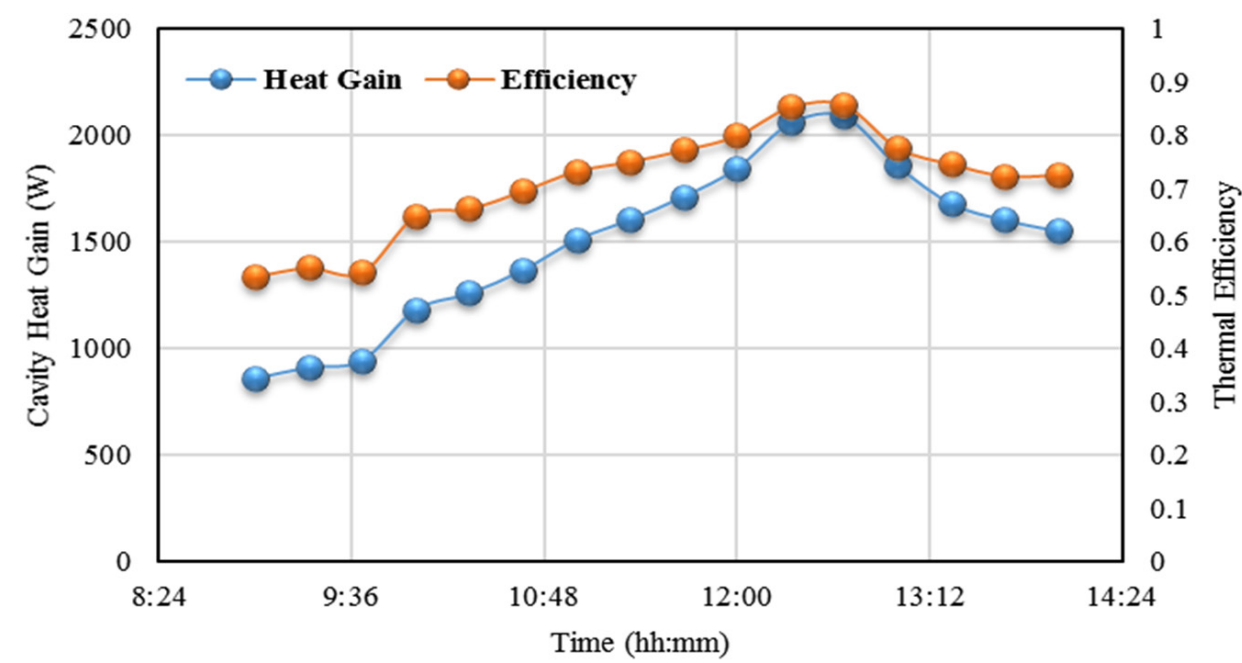

Figure 25. Variation in cavity heat gain and thermal efficiency of the solar system during the experimental day 29 September 2017, with thermal oil as the solar working fluid.

\subsection{Solar Dish Performance and Impact of Combination with Harvester}

The following section deals with reporting the results derived from the performance of the solar dryer in the case where $\mathrm{Al}_{2} \mathrm{O}_{3}$ /thermal oil nanofluid was used as the solar working fluid. The extent to which the measured environmental and conditional parameters varied was represented throughout the stages of experimental tests. The time in which the experimental tests were performed was through 9:00 to 14:00 on days 29 and 30 of 
September, 2020, and the solar working fluids were categorized by $15 \mathrm{~mL} / \mathrm{s}$ volume flow rate.

The performance of the solar dryer system was reported with the $\mathrm{Al}_{2} \mathrm{O}_{3}$ /thermal oil nanofluid as the solar working fluid of the cylindrical cavity receiver. The nanofluid was tested at a mass fraction of $0.8 \%$. At $0.5 \mathrm{~m} / \mathrm{s}, 1 \mathrm{~m} / \mathrm{s}$, and $1.5 \mathrm{~m} / \mathrm{s}$ air speed as well as at $30^{\circ} \mathrm{C}$, $40{ }^{\circ} \mathrm{C}$, and $50^{\circ} \mathrm{C}$ drying temperature conditions, the drying system and the solar system were investigated, respectively. Figure 26 illustrates how the olive fruit drying time differs at different air speeds and drying temperatures. As the drying temperature and air speed increase, the drying time pertaining to the olive fruit decreases, as represented through Figure 26. At $0.5 \mathrm{~m} / \mathrm{s}$ air speed and $30{ }^{\circ} \mathrm{C}$ drying temperature, the highest decreasing moisture time was obtained. However, at $1.5 \mathrm{~m} / \mathrm{s}$ air speed and $50{ }^{\circ} \mathrm{C}$ drying temperature, the lowest drying time was obtained. Thus, as the time of experimental test increased, the drying time increased accordingly. This can be attributed to the evaporation of the surface moisture, thus initiating the quicker drying process. As time passes, the surface moisture remains with no content, and the internal moisture must be evaporated. Therefore, such a process uses more time for evaporation when it is compared to the case of surface moisture evaporation.
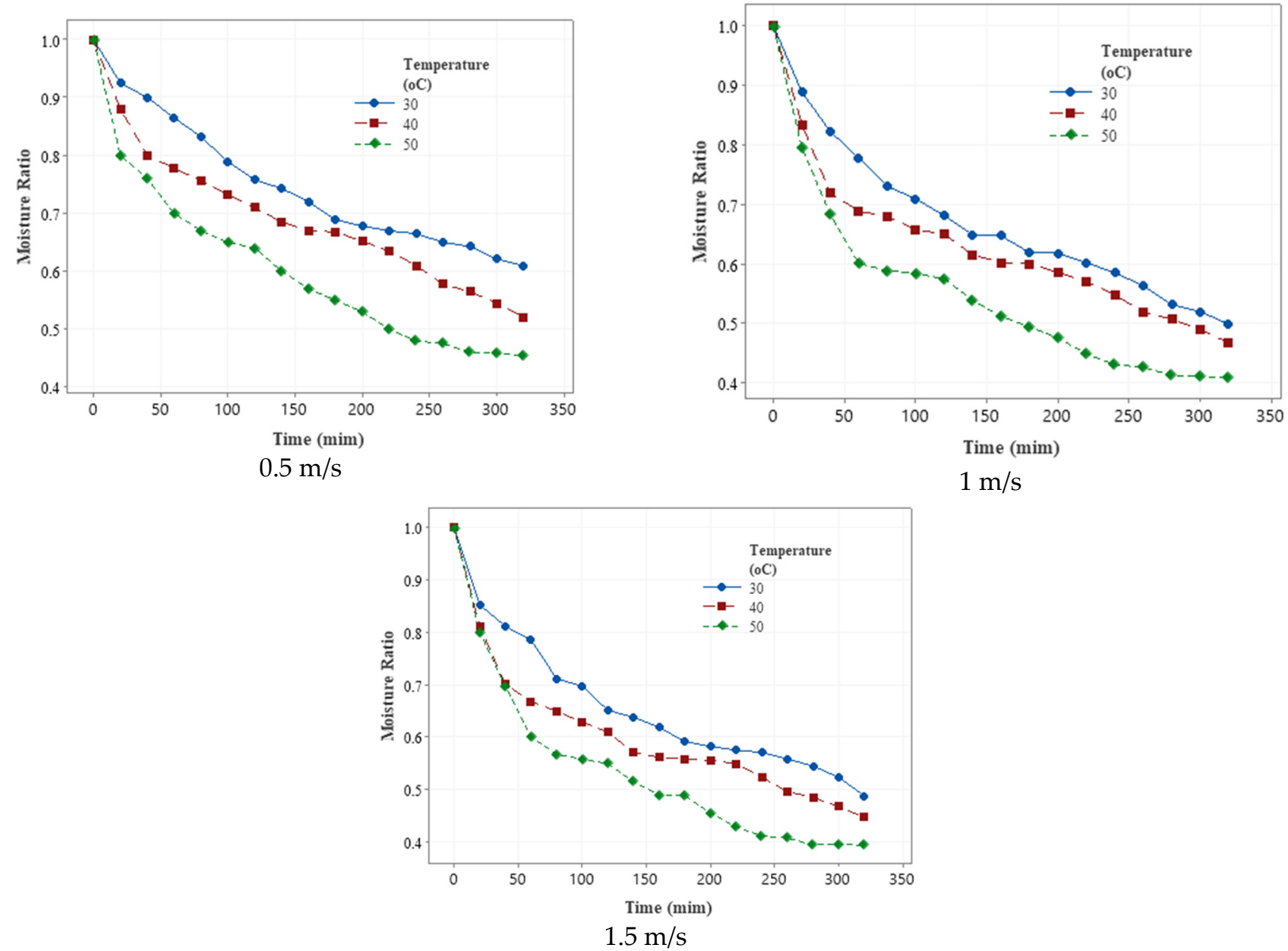

Figure 26. A olive fruit drying graph at air speed of $0.5,1$, and $1.5 \mathrm{~m} / \mathrm{s}$ and different drying temperatures.

Many traditional olive groves far from the network often have a place to store olives for other seasons. The appropriate moisture for storing an olive is half of its initial moisture. Accordingly, farmers have to send freshly picked fruits to dry storage centers and then transport them to storage facilities or traditionally expose them to sunlight in the open 
air to reduce moisture. The traditional method of reducing the moisture of olives is often time-consuming, and transferring the fruits to the drying centers and returning the fruits to the warehouse bring about wastage of money, energy and hard work. The combination of two harvesting and drying operations in the garden reduces the energy consumption to zero as a result of the transfer. On the other hand, renewable energy is used for drying.

\section{Conclusions}

It is taken for granted that harvesting takes the first priority when the goal is to farm olives, and quality of harvesting is dependent on the device used in this regard. In the present research work, initially, the effect of harvester jaw on olive fruit was simulated, and the jaw was analyzed in terms of the best angular velocity. In order to show how the new pneumatic harvester could outperform when compared to its counterparts in the market, an analysis in this field was attempted. Concerning the $4.52 \%$ fruit ripening index, it is feasible to claim that only $8 \%$ of olive fruits remained on the trees. It was found that the HP was $29.47 \mathrm{~kg} / \mathrm{h}$, indicating that $92 \%$ of the tree olives can be detached by NPH in a short time. Thanks to its usability and suitable working conditions, such a machine is traditionally practical. The major part of the energy is used in olive moisture reduction process for the traditional orchards with distant energy network, manual harvesting process, transfer to the desiccators' location, and return to farmer. An integration of on-site energy and time-consuming processes can reduce the consumed energy for harvesting and moisture reduction. In this case, more time is saved, and the collector system impedes further damage to the olive fruit, which makes it easier to use in various harvesting methods. Another note to be taken is addressing the issue of how the solar drying system works using the $\mathrm{Al}_{2} \mathrm{O}_{3}$ /oil nanofluid. The increase in drying temperature and air speed resulted in decreased olive fruit moisture drying time. The reason lies in the fact that there are higher heat transfer rates under these operating conditions. Under $0.5 \mathrm{~m} / \mathrm{s}$ air speed and $30{ }^{\circ} \mathrm{C}$ drying temperature conditions, the highest drying time $(320 \mathrm{~min})$ was achieved. However, under $1.5 \mathrm{~m} / \mathrm{s}$ air speed and $50{ }^{\circ} \mathrm{C}$ drying temperature conditions, the lowest drying time was obtained.

Author Contributions: F.Z.; writing—original draft preparationdata curation G.N.; supervision, project administration, funding acquisition, investigation, resources P.G.; software, validation, formal analysis E.F.; Conceptualization, methodology T.Y.; writing-review and editing; visualization M.M.; writing-review and editing. All authors have read and agreed to the published version of the manuscript.

Funding: This research received no funding.

Institutional Review Board Statement: Not applicable.

Informed Consent Statement: Not applicable.

Data Availability Statement: Not applicable.

Acknowledgments: This research was supported by Iran National Science Foundation (INSF) with 92032254 number. We thank our colleagues from INSF who provided insight and expertise that greatly assisted the research and appreciation to Universiti Malaysia Kelantan Rising Star Research Grant (R/STA/A1300/00929A/005/2021/00926).

Conflicts of Interest: The funders had no role in the design of the study; in the collection, analyses, or interpretation of data; in the writing of the manuscript; or in the decision to publish the results.

\section{References}

1. Ghobadian, B.; Najafi, G.; Rahimi, H.; Yusaf, T. Future of renewable energies in Iran. Renew. Sustain. Energy Rev. 2009, 13, 689-695. [CrossRef]

2. Assali, A.; Khatib, T.; Najjar, A. Renewable energy awareness among future generation of Palestine. Renew. Energy 2019, 136, 254-263. [CrossRef]

3. Kartite, J.; Cherkaoui, M. Study of the different structures of hybrid systems in renewable energies: A review. Energy Procedia 2019, 157, 323-330. [CrossRef] 
4. $\quad$ Phillips, L. Solar energy. In Managing Global Warming: An Interface of Technology and Human Issues; Letcher, T.M., Ed.; Elsevier: Amsterdam, The Netherlands, 2018; pp. 317-332.

5. Kalogirou, S.A. Solar thermal collectors and applications. Prog. Energy Combust. Sci. 2004, 30, 231-295. [CrossRef]

6. Barbera, A.C.; Maucieri, C.; Cavallaro, V.; Ioppolo, A.; Spagna, G. Effects of spreading olive mill wastewater on soil properties and crops, a review. Agric. Water Manag. 2013, 119, 43-53. [CrossRef]

7. Fiorino, P.; Marone, E.; Ottanelli, A. Mechanical Harvesting, Productivity and Superintensive Planting Systems in Olive Groves. Adv. Hortic. Sci. 2010, 24, 91-94.

8. Lupi, F.R.; Gabriele, D.; Facciolo, D.; Baldino, N.; Seta, L.; de Cindio, B. Effect of organogelator and fat source on rheological properties of olive oil-based organogels. Food Res. Int. 2012, 46, 177-184. [CrossRef]

9. Ottanelli, A.; Marone, E.; Fiorino, P. A new device to improve the mechanical winter pruning in olive trees hedgerows. Adv. Hortic. Sci. 2019, 33, 113-122.

10. Zipori, I.; Dag, A.; Tugendhaft, Y.; Birger, R. Mechanical harvesting of table olives: Harvest efficiency and fruit quality. HortScience 2014, 49, 55-58. [CrossRef]

11. Ahmad, R.L. Efficiency of mechanical tools for olive harvest and effect on fruit quality. Acta Hortic. 2018, 1199, 315-319. [CrossRef]

12. Mansour, H.A.; Elmesiry, T.A.; Abdelhady, A.A. The Effect of Operating Speed and Olive Varieties Harvested by Hand-Held Machine on Productivity and Damage Percentage. World Wide J. Multidiscip. Res. Dev. 2018, 4, 355-360.

13. Plasquy, E.; Sola-Guiraldo, R.R.; Florido, C.; García, J.M.; Blanco-Roldán, G. Evaluation of a manual olive fruit harvester for small producers. Res. Agric. Eng. 2019, 65, 105-111. [CrossRef]

14. Sola-Guirado, R.R.; Castillo-Ruiz, F.J.; Blanco-Roldan, G.L. Mechanical canopy and trunk shaking for the harvesting mechanization of table olive orchards. Revista Facultad Ciencias Agrarias UNCuyo 2020, 52, 124-139.

15. Loni, R.; Kasaeian, A.; Shahverdi, K.; Asli-Ardeh, E.A.; Ghobadian, B.; Ahmadi, M.H. ANN model to predict the performance of parabolic dish collector with tubular cavity receiver. Mech. Ind. 2017, 18, 408. [CrossRef]

16. Loni, R.; Kasaeian, A.; Mahian, O.; Sahin, A. Thermodynamic analysis of an organic rankine cycle using a tubular solar cavity receiver. Energy Convers. Manag. 2016, 127, 494-503. [CrossRef]

17. Pavlovic, S.; Loni, R.; Bellos, E.; Vasiljević, D.; Najafi, G.; Kasaeian, A. Comparative study of spiral and conical cavity receivers for a solar dish collector. Energy Convers. Manag. 2018, 178, 111-122. [CrossRef]

18. Loni, R.; Asli-Ardeh, E.A.; Ghobadian, B.; Bellos, E.; Le Roux, W.G. Numerical comparison of a solar dish concentrator with different cavity receivers and working fluids. J. Clean. Prod. 2018, 198, 1013-1030. [CrossRef]

19. Venkatachalam, T.; Cheralathan, M. Effect of aspect ratio on thermal performance of cavity receiver for solar parabolic dish concentrator: An experimental study. Renew. Energy 2019, 139, 573-581. [CrossRef]

20. Yan, J.; Peng, Y.-d.; Cheng, Z.-r. Optimization of a discrete dish concentrator for uniform flux distribution on the cavity receiver of solar concentrator system. Renew. Energy 2018, 129, 431-445. [CrossRef]

21. Yang, S.; Wang, J.; Lund, P.D.; Jiang, C.; Huang, B. Design and performance evaluation of a high-temperature cavity receiver for a 2-stage dish concentrator. Sol. Energy 2018, 174, 1126-1132. [CrossRef]

22. Loni, R.; Kasaeian, A.; Asli-Ardeh, E.A.; Ghobadian, B.; Le Roux, W. Performance study of a solar-assisted organic Rankine cycle using a dish-mounted rectangular-cavity tubular solar receiver. Appl. Therm. Eng. 2016, 108, 1298-1309. [CrossRef]

23. Karimi, R.; Gheinani, T.T.; Avargani, V.M. A detailed mathematical model for thermal performance analysis of a cylindrical cavity receiver in a solar parabolic dish collector system. Renew. Energy 2018, 125, 768-782. [CrossRef]

24. Pavlovic, S.; Bellos, E.; Loni, R. Exergetic investigation of a solar dish collector with smooth and corrugated spiral absorber operating with various nanofluids. J. Clean. Prod. 2018, 174, 1147-1160. [CrossRef]

25. Elsheikh, A.; Sharshir, S.; Mostafa, M.E.; Essa, F.; Ali, M.K.A. Applications of nanofluids in solar energy: A review of recent advances. Renew. Sustain. Energy Rev. 2017, 82, 3483-3502. [CrossRef]

26. Xuan, Y.; Li, Q. Heat transfer enhancement of nanofluids. Int. J. Heat Fluid Flow 2000, 21, 58-64. [CrossRef]

27. Verma, S.K.; Tiwari, A.K. Progress of nanofluid application in solar collectors: A review. Energy Convers. Manag. 2015, 100, 324-346. [CrossRef]

28. Mahbubul, I.; Khan, M.M.A.; Ibrahim, N.I.; Ali, H.M.; Al-Sulaiman, F.A.; Saidur, R. Carbon nanotube nanofluid in enhancing the efficiency of evacuated tube solar collector. Renew. Energy 2018, 121, 36-44. [CrossRef]

29. Loni, R.; Asli-Ardeh, E.A.; Ghobadian, B.; Najafi, G.; Bellos, E. Effects of size and volume fraction of alumina nanoparticles on the performance of a solar organic Rankine cycle. Energy Convers. Manag. 2019, 182, 398-411. [CrossRef]

30. Loni, R.; Asli-Ardeh, E.A.; Ghobadian, B.; Kasaeian, A.; Bellos, E. Thermal performance comparison between $\mathrm{Al}_{2} \mathrm{O}_{3} / \mathrm{oil}_{\text {and }}$ $\mathrm{SiO}_{2}$ /oil nanofluids in cylindrical cavity receiver based on experimental Study. Renew. Energy 2018, 129, 652-665. [CrossRef]

31. Loni, R.; Asli-Ardeh, E.A.; Ghobadian, B.; Kasaeian, A.; Bellos, E. Energy and exergy investigation of alumina/oil and silica/oil nanofluids in hemispherical cavity receiver: Experimental Study. Energy 2018, 164, 275-287. [CrossRef]

32. Mohsenin, N.N. Physical Properties of Plant and Animal Materials; Taylor and Francis: New York, NY, USA, 1986.

33. Ghaffari, H.; Hassanpor, H.; Marghoub, N.; Mohammadi, K. Evaluation of some mechanical properties of two varieties persimmon in order to improve post-harvest systems at different ripening stages. J. Food Res. 2020, 30, 183-194.

34. Polat, R.; Gezer, I.; Guner, M.; Dursun, E.; Erdogan, D.; Bilim, H.C. Mechanical harvesting of pistachio nuts. J. Food Eng. 2007, 79, 1131-1135. [CrossRef] 
35. Srivastava, A.K.; Goering, C.E.; Rohrbach, R.P.; Buckmaster, D.R. Engineering Principles of Agricultural Machines, 2nd ed.; American Society of Agricultural and Biological Engineers: St. Joseph, MI, USA, 2006.

36. Baghernejad, A.; Yaghoubi, M. Thermoeconomic methodology for analysis and optimization of a hybrid solar thermal power plant. Int. J. Green Energy 2013, 10, 588-609. [CrossRef]

37. Ilyas, S.U.; Pendyala, R.; Narahari, M.; Susin, L. Stability, rheology and thermal analysis of functionalized alumina-thermal oil-based nanofluids for advanced cooling systems. Energy Convers. Manag. 2017, 142, 215-229. [CrossRef]

38. Yazid, M.N.A.W.M.; Sidik, N.A.C.; Mamat, R.; Najafi, G.J.I.C.i.H.; Transfer, M. A review of the impact of preparation on stability of carbon nanotube nanofluids. Int. Commun. Heat Mass Transf. 2016, 78, 253-263. [CrossRef]

39. Kermani, A. Comparison of Four Harvesting Machines for Harvesting of Oil Olive. J. Eng. Res. Agric. Mech. Syst. 2016, 16, 1-18.

40. Ettefaghi, E.; Ghobadian, B.; Rashidi, A.; Najafi, G.; Rashtchi, M.; Sadeghian, S. A novel bio-nano emulsion fuel based on biodegradable nanoparticles to improve diesel engines performance and reduce exhaust emissions. Renew. Energy 2018, 125, 64-72. [CrossRef] 